Journal of Geophysical Research, 105, pp 11,279-11,297, 2000.

\title{
Self-adapting open boundaries for a sigma coordinate model of the eastern North Atlantic
}

\author{
Thierry Penduff and Bernard Barnier
}

Laboratoire des Ecoulements Géophysiques et Industriels, Grenoble, France

Alain Colin de Verdière

Laboratoire de Physique des Océans, Université de Bretagne Occidentale, Brest, France

\begin{abstract}
A regional non-eddy-resolving configuration of the SPEM5.1 primitive equation model is used to study the dynamics of the eastern North Atlantic. Along most of the domain perimeter, extensive open boundaries (OBs) evacuate outgoing perturbations, while the outer ocean is simulated by lateral relaxation of some of the model variables. Unlike in existing regional models, this lateral constraint only concerns the tracers and the baroclinic velocities, for which good climatological estimates exist. Along the OBs, the barotropic stream function is entirely determined by the model response to the inner dynamics, without relaxation to any questionable a priori estimate. The adjustment processes and their interaction with the open boundaries are described. The final solution is remarkably stable and quite realistic. The net transports crossing the boundaries are prescribed; we therefore investigated the impact of these parameters. We first show that the prescribed mass exchange between the basin and the rest of the Atlantic has almost no influence on the interior circulation since the western and southern lateral conditions naturally adjust to the interior dynamics. The net circulation constrained around Iceland, however, has large-scale consequences: Through the intensity of the overflow above the Iceland-Scotland Ridge (ISR), this parameter affects the stratification north and south of the Rockall Plateau, the subpolar dynamics, and finally the North Atlantic Current path up to the Charlie Gibbs Fracture Zone. This slowly propagating dynamical effect, already noticed in previous studies, is shown to be forced baroclinically near the ISR.
\end{abstract}




\section{Introduction}

Numerical studies of ocean dynamics are mostly conducted on subbasins of the world ocean, thus avoiding the use of complex and expensive global models. However, the presence of the ocean outside the basin of interest needs to be simulated artificially along the boundaries of such regional models. This goal may be achieved provided that the boundary conditions used around open domains fulfill the following requirements:

1. The perturbations (waves, eddies, other propagating structures) generated inside the domain should be able to leave the subdomain as naturally as possible.

2. The influence of the outer ocean on the computational domain must be simulated by a lateral forcing, when and where necessary.

3. Since local processes affect the outer ocean, the lateral forcing of a regional model should be allowed to adjust to the interior dynamics instead of being prescribed.

Until now, only the first and second requirements have been more or less fulfilled in regional model applications. The third objective has basically never been achieved.

Many basin-scale numerical configurations are limited by closed boundaries through which the mass and tracer fluxes are zero (as in the Community Modeling Effort model experiments [Bryan and Holland, 1989], and in two models of the Dynamics of North Atlantic Models experiment [DYNAMO Group, 1997]). The thermohaline circulation is then driven by a relaxation of tracers to a climatology in so-called "buffer zones" adjacent to these walls. This approach is very simple, but has certain limitations. First, it is only possible when the integrated mass flux across the boundary is zero. A second limitation is that it creates a necessarily unrealistic transition region of water mass transformation near the walls, the effect of which is difficult to evaluate. Third, the interior dynamics and thermodynamics strongly depend on the tracer relaxation to the climatology near closed boundaries [Böning et al., 1996; Döscher and Redler, 1997], and finally, the outgoing perturbations can only be damped in an imperfect manner. These four problems can be avoided and the first requirement can be fulfilled by the use of open boundaries. They are mostly based on radiation conditions such as those proposed by Sommerfeld [1949] or Orlanski [1976], but their tuning is known to be complex [Stevens,
1990; Palma and Matano, 1998].

A relaxation term may be added at the right-hand side of such radiation conditions [Blumberg and Kantha, 1985; Stevens, 1990] to simultaneously evacuate perturbations outward and force the interior dynamics (then the first two requirements are fulfilled); model variables are relaxed or prescribed to climatological values. However, this solution requires a reliable climatic estimate for each relaxed variable, and such estimates only exist for the baroclinic variables (temperature, salinity, and associated baroclinic velocities via the thermal wind). The vertically integrated circulation (hereafter referred to as "barotropic" and denoted $\psi$ ) is indeed poorly known in the real ocean; at best, it can be roughly estimated from the Sverdrup relation, or taken from previous model results.

Stevens and Johnson [1997] used such radiation relaxation conditions for the tracers around an eastern North Atlantic domain, and prescribed $\psi$ to different a priori profiles (a Sverdrup- and a model-derived lateral climatology). Their results reveal inconsistencies between the interior dynamics and the lateral forcing, probably because $\psi$ was prescribed along the perimeter. Barnier et al. [1998] (noted B98 hereafter) presented a numerical solution to partially fulfill the third requirement: In the event of outflow, $\psi$ could adjust along the open boundaries via a radiation condition. In inflow regions, however, $\psi$ was strongly relaxed to an a priori profile: The location and strength of all prescribed incoming currents, and the local and integrated tracer fluxes, were strongly constrained laterally, and the inner solution was influenced by the partly arbitrary lateral $\psi$ profile.

Our final objective is to study the dynamics of the eastern North Atlantic with a regional model. Such a numerical configuration requires the use of open boundaries, since the basin exchanges many water masses with the rest of the Atlantic above the MidAtlantic Ridge (MAR), across $30^{\circ} \mathrm{N}$, and with the Nordic Seas above the Greenland-Iceland-Scotland Ridge. The existing open boundary conditions presented above require an a priori knowledge of the model variables; climatologies provide reasonable estimates for the tracers and baroclinic velocities, but the $\psi$ profile along the basin limits is almost unknown. Therefore the possibility of the lateral dynamical forcing adjusting to the interior dynamics (the third requirement) should prove particularly fruitful in obtaining a realistic numerical solution in this particular subbasin. 
The next section presents the coarse grid configuration of the SPEM5.1 model selected to study the basin dynamics. In section 3 we describe the lateral forcing of the model and comment on the fulfillment of the third requirement; we will show that no climatological $\psi$ lateral profile is needed along the open boundaries, since $\psi$ adjusts to the interior dynamics along them. The adjustment of the basin and the behavior of the open boudaries during this process are investigated in section 4 . In section 5 we examine the sensitivity of the interior solution to the lateral forcing; in particular, the intensity of the dense overflow between Iceland and Scotland is shown to affect the subpolar circulation (as in previous studies), and we propose an explanation for this remote effect. The results are summarized in section 6 .

\section{Model and Configuration}

\subsection{The SPEM Model}

The numerical simulations were performed with SPEM5.1, a primitive equation ocean circulation model developed by Haidvogel et al. [1991]. This model uses the rigid lid approximation and sigma coordinates in the vertical: The computational sigma levels are distributed between the flat sea surface and the irregular ocean bottom, two solid boundaries where the normal velocities are set to zero. The model has been adapted by Marchesiello [1995], B98, and Marchesiello et al. [1998] for basin-scale simulations with open boundaries, and used in a closed North Atlantic configuration by the DYNAMO Group [1997]. More details about the model formulation are given in these papers.

\subsection{Computational Domain, Grid, and Bathymetry}

The computational domain (Figure 1) is surrounded by open boundaries (OBs) at its western, southern, and eastern limits. Derived from B98, these OBs are designed to simultaneously evacuate outgoing perturbations and simulate the presence of the outer ocean by exerting a lateral forcing when needed (see section 3). As already noticed by Stevens [1990], and as suggested by several simulations performed with SPEM on different South Atlantic configurations [B98; Marchesiello et al., 1998; de Miranda et al., 1999] the achievement of these goals is promoted when tangential velocities remain low along the OBs. We thus set the depth gradient normal to the boundaries to zero, and placed the OBs perpendicularly to the main incoming currents.

The western open boundary was accordingly placed at $40^{\circ} \mathrm{W}$, downstream of Newfoundland Basin, where the northward flowing North Atlantic Current (NAC) is very turbulent and has a complex structure, and downstream of the so-called Northwestern Loop where the current steers eastward (see Figure 1). At $40^{\circ} \mathrm{W}$ the boundary is approximately normal to the NAC and to the Azores Current (AC) that flows eastward along $33^{\circ} \mathrm{N}$, and is a long way from the MAR western sloping flank.

The northern limit of the domain intersects Iceland along $66.5^{\circ} \mathrm{N}$ and was split into two fixed boundaries (see section 3). Its western half is situated beyond the Denmark Strait overflow region. The southern open boundary is located at $30^{\circ} \mathrm{N}$ to include the $\mathrm{AC}$ and the region where the Mediterranean Water (MW) overflows into the Atlantic. The Gibraltar Strait is closed, but the influence of the MW on the Atlantic water masses is simulated by a relaxation of tracers at all depths in the Gulf of Cadiz (timescale of 80 to 30 days). The southern boundary is crossed mainly by the southward recirculation of the subtropical gyre. The eastern open boundary is located at $0.8^{\circ} \mathrm{W}$ and is crossed mainly by an outgoing NAC branch. We put artificial islands at the southwestern and northeastern corners of the domain, as explained in section 3.

The elementary horizontal grid is square and has a coarse resolution of $0.8^{\circ}$ in longitude and $0.8^{\circ} \times \cos (\phi)$ in latitude $(\phi)$; the eddies are not resolved. Twentyone sigma levels are used on the vertical, with an increased resolution near the surface (Table 1).

The bathymetry actually used in the simulations is derived from the ETOPO5 data set and shown in Figure 1. As explained by B98, it was smoothed so as to reduce the spurious velocities due to discretization errors in the pressure gradient term.

\subsection{Initial Stratification, Surface Forcing, and Parametrizations}

The initial stratification is taken from the recent Reynaud et al. [1998] seasonal climatology (noted RLM hereafter). It exhibits marked horizontal density fronts and is then particularly interesting with respect to the lateral forcing (see section 3). The surface and lateral fluxes also depend on this climatology: The seasonal heat forcing is derived from the method of Barnier et al. [1995] (but the European Centre for Medium-Range Weather Forecasts (ECMWF) heat flux is corrected by relaxing the model surface tem- 
perature to the RLM fields); the freshwater flux is simulated by relaxing the model surface salinity to the RLM climatology. The wind stresses come from the Hellermann and Rosenstein [1983] monthly climatology. These surface forcings are applied as body forces on $50 \mathrm{~m}$.

Laplacian lateral diffusive and frictional fluxes along geopotential surfaces are chosen. Their coefficients vary inversely to the grid size to keep the Reynolds number constant: From south to north, diffusion ranges from 875 to $400 \mathrm{~m}^{2} \mathrm{~s}^{-1}$, and viscosity from 3000 to $1600 \mathrm{~m}^{2} \mathrm{~s}^{-1}$. Vertical viscosity and diffusion coefficients are equal to $10^{-4} \mathrm{~m}^{2} \mathrm{~s}^{-1}$ everywhere, but multiplied by 10 in the first $50 \mathrm{~m}$ where the surface forcing is applied. Possible static instabilities are removed at each time step by locally increasing the vertical diffusion up to $1 \mathrm{~m}^{2} \mathrm{~s}^{-1}$, and by making daily convective adjustments, if necessary.

\section{Lateral Forcing}

Since land points are required at the intersection of radiative boundaries, artifical islands were introduced at the southwestern and northeastern corners of the domain, where the main currents are expected to be weak.

Along the domain perimeter the RLM climatology provides reliable seasonal estimates for the temperature, salinity, and vertical shear of the normal velocity field (i.e., the normal baroclinic velocities) derived from the thermal wind relation. The exchanges between the computational domain and the surrounding ocean are partly dependent on this baroclinic climatology and are simulated by open boundary conditions at western, eastern, and southern limits.

Along latitude $66^{\circ} \mathrm{N}$, however, open boundaries were unable to deal with resonant inertial modes triggered at initialization in the Irminger and Norwegian Seas. We thus decided to drop out the radiation conditions and to use robust fixed boundary conditions west and east of Iceland: The baroclinic variables are prescribed to their seasonal climatology during the whole integration, and $\psi$ is prescribed to a stationary profile that varies linearly between its constant values on Greenland, on Iceland, and on the northeastern artificial island.

\subsection{The Original SPEM Open Boundary Conditions}

Marchesiello [1995] and B98 gave a complete description of the open boundary conditions that they implemented in SPEM. Every variable $\phi$ is treated as follows: Outgoing perturbations of $\phi$ are evacuated by a radiation condition based on the wave equation of Raymond and Kuo [1984]. The parameter $c^{\phi}$, their phase speed normal to the boundary, is evaluated at every time step and at every point of the open boundary by equation (5-a) of B98 $\left(c^{\phi}\right.$ is corrected by an advection velocity $u_{a}$ if $\phi$ is a tracer, as Stevens [1990] did). A Blumberg and Kantha [1985]-type relaxation term to a climatology is added to the right-hand side of the radiation equations to simulate the presence of the outer ocean. The relaxation timescale depends on the $\phi$ variable considered and on the sign of the phase/advection velocity $c^{\phi}$ of its perturbations. At the points where $c^{\phi}$ is directed outwards an outflow situation is diagnosed for the $\phi$ variable: The perturbation is radiated outward with a weak relaxation of $\phi$ to the climatology. Otherwise, an inflow regime is diagnosed: No radiation occurs and $\phi$ is strongly relaxed to the climatology.

It is important to note that even where currents flow into the basin, upstream waves can be directed outward and create an outflow situation; the distinction between inflow and outflow regimes is not based on the sign of the local velocity, but on the direction of the information, itself influenced by the velocity field.

\subsection{The Self-Adapting Open Boundary Conditions Used Here}

Along our western, southern, and eastern open boundaries, the treatment of the baroclinic variables (temperature $T$, salinity $S$, and normal baroclinic velocity $u_{x}^{\prime}$ ), and of the total tangential velocity $u_{y}$ is similar to the original B98 algorithm. Relaxing $T$ and $S$ in inflow regions is necessary to prescribe the characteristics of incoming water masses, taken from the RLM climatology. A B98-like prescription of $u_{x}^{\prime}$ in the event of inflow also seems legitimate, because a good estimate can be derived from the RLM fields. Table 2 gives the timescales $\tau$ used in all cases.

As in B98, we had to impose the net mass flux crossing each open boundary by prescribing the values of $\psi$ on the land points (continents or artificial islands) that limit the open boundaries. These constant integrated transports were adjusted empirically to match the existing estimates and the model dynamics (see sections 3.4 and 5).

Unlike the baroclinic variables, any relaxation of $\psi$ is questionable since no reliable climatology exists for it. We therefore let the model adjust by itself the 
$\psi$ profile (and therefore the barotropic normal velocity distribution) along the open boundaries: Outgoing barotropic perturbations are radiated away in outflow regions by the original algorithm, but no relaxation is added to the right-hand side of the barotropic radiation equation, whatever the sign of the phase speed of the barotropic perturbations. This is the principal modification made to the original SPEM open boundary conditions.

Stevens [1990] tested a similar technique for $\psi$ in a short integration of an idealized model (flat-bottomed rectangular basin without surface forcing or meridional open boundary); this numerical solution, however, was not retained in the subsequent basin-scale experiments [Stevens, 1991] where $\psi$ was prescribed to a Sverdrup-derived profile. The following section explains the physical interest of dropping the local constraints on $\psi$ along the open boundaries for the long-term adjustment of this more complex model.

\subsection{Physical Interest}

Away from the northern boundary where all variables are imposed, the barotropic circulation in the interior and along the open boundaries adjusts to the interior dynamics, to surface forcings, to the lateral baroclinic climatologies, and to the prescribed net through flows. In return, the barotropic mode can modify the phase speed of the perturbations of all variables via the background advection, and can therefore affect the location of inflows and outflows along the open boundaries: The number, strength, and position of the incoming currents are not constrained through $\psi$ along the OBs. Even though barotropic currents are almost unknown in the real ocean, prognostic regional models used to date strongly control this field in inflow regions by a strong relaxation of $\psi$ to a model- or Sverdrup-derived a priori profile. The present method simulates the impact of the interior dynamics on the surrounding ocean, avoids the construction of any a priori $\psi$ profile along the open boundaries, and fulfills the three requirements identified in the introduction.

\subsection{Choice of the Net Lateral Mass Fluxes for the Reference Run}

This net mass flux prescription does not affect the circulations that enter and exit the basin across the same open boundary, but only the net mass flux that transits from one boundary to another. As the transport across the Bering Strait is neglected, the water crossing the southern (respectively, northwestern) limit of the domain necessarily comes from the western (respectively, eastern) boundary within the subtropical anticyclonic (respectively, nordic seas cyclonic) gyre: The net mass fluxes to be constrained are condensed into the three loops displayed in Figure 2, for which we estimated a priori intensities.

1. The intensity of the anticyclonic subtropical loop $I_{\text {SUBTROP }}$ quantifies the net mass exchange between the basin and the rest of the Atlantic. According to some inverse models [Mercier at al., 1993; Paillet and Mercier, 1997], the integrated transport across $30^{\circ} \mathrm{N}$ reaches $30 \mathrm{~Sv}$. However, only a value of $10 \mathrm{~Sv}$ is reported in the three DYNAMO Group [1997] models, and a value of $15 \mathrm{~Sv}$ is proposed by Bryan et al. [1995] from three simulations forced by different winds. We therefore gave $I_{\text {SUBTROP }}$ an a priori value of $15 \mathrm{~Sv}$.

2. The net southward flow through the Denmark Straits and the net northeastward flow between Iceland and Scotland were estimated by Worthington [1970] to be $6 \mathrm{~Sv}$; this value was taken as an a priori estimate for $I_{\mathrm{SUBPOL}}$, the intensity of the cyclonic subpolar loop around Iceland.

3. The circulation schemes proposed by Dietrich et al. [1975] and Krauss [1986] exhibit a 2-Sv cyclonic circulation around the northeastern corner; the same value was taken as the a priori intensity of this northeastern loop.

In section 5 we shall see how the model solution depends on these parameters and explain why the intensity of the subpolar loop was not set to its a priori value for the reference simulation. Table 3 summarizes the a priori intensity of the three loops drawn in Figure 2 and of the integrated transports across the five boundaries. This table also presents the value of those parameters in the reference simulation and in the four sensitivity experiments presented in section 5 .

\section{Initial Conditions, Adjustment, Stabilization, and Final State}

\subsection{Initial Conditions}

The initial temperatures and salinities are taken from the monthly interpolated RLM climatology for January. The baroclinic velocity field is initially set to zero and is expected to build up rapidly through geostrophic adjustment. The initial barotropic stream function can be determined by the model elliptic
Figure 2

Table 3 
solver, given the interior barotropic vorticity initial field (zero) and a $\psi$ continuous arbitrary profile around the perimeter. The latter profile is built by a simple linear interpolation between $\psi$ land values; this sketch naturally leads to an unrealistic $\psi$ initial field (Figure 3), but is quickly reshaped by adjustment processes.

\subsection{Adjustment Processes and Timescales}

4.2.1. Short-term adjustment. On a $1 / \mathrm{f}$ timescale, several processes take place simultaneously. With a release of inertial-gravity waves, geostrophic adjustment generates baroclinic velocities, corrected by the Ekman drift distributed over the top $50 \mathrm{~m}$; barotropic velocities emerge locally from pumping at the base of the Ekman layer and at the bottom where the horizontal velocity interacts with topographic slopes; and fast barotropic Rossby waves, traveling mostly westward along $f / H$ contours (Figure 4), adjust these local values of $\psi$ to the basin geometry and to the large-scale forcing.

Figure 5 shows that these processes strongly modify $\psi$ to produce the expected subpolar and subtropical gyres separated by the North Atlantic Current (NAC). The intense and fast propagating barotropic waves excited at the start are well evacuated outward, since no suspect distortion of $\psi$ appears nor remains along the open boundaries. As shown by a barotropic vorticity analysis, after 2 days $\psi$ reaches a state where the cross- $f / H$ flow $J(\psi, f / H)$ approximately balances the vorticity sources that were imposed at the start: The Ekman pumping $\nabla \times(\tau / H)$, and the joint effect of baroclinicity and relief (JEBAR effect). This latter term quantifies the correction made by the stratification on the interaction between $\psi$ and topography [Mertz and Wright, 1992]. It is expressed as follows:

$$
\mathrm{JEBAR}=J\left(E, \frac{1}{H}\right),
$$

where $J$ is the Jacobian operator, $H$ is the local depth, and $E=\int_{-H}^{0} \rho z d z$ is the potential energy of the stratification. JEBAR is mainly controlled by the seasonal tracer fluxes at the surface and along the boundaries.

These processes drastically change the initial $\psi$ sketch into a realistic field that remains subjected to slower baroclinic adjustment (through JEBAR) during the rest of the integration.

4.2.2. Medium-term adjustment. Surface buo-yancy fluxes, stratification and circulation within the mixed layer are strongly correlated, but they are not necessarily consistent at the start. They are therefore expected to adjust and reach an equilibrium. We focus on the adjustment of the North Atlantic Central Water (NACW) and of the Subpolar Mode Water (SPMW), two important water masses of the upper eastern North Atlantic: The NACW $\left(26.9<\sigma_{0}<27.2\right)$ [see Arhan et al., 1994] enters the domain with the NAC, loses buoyancy in winter, and is progressively changed into SPMW. Dense varieties of SPMW are advected toward colder areas and quit the domain, but ventilation processes feed one of the most prominent features of the eastern basin's stratification: The subducted SPMW tongue, which extends southward between $\sigma_{0}=27.0$ and $\sigma_{0}=27.3$. The water masses of the top $1000 \mathrm{~m}$ were sorted by neighboring $0.1 \mathrm{~kg} \mathrm{~m}^{-3}$-wide density classes. The upper plots of Figure 6 show the individual volumes of those water masses at the start and after 6 and 38 years of integration. The lower plots show the relative variation (in percent) of those quantities after 6 and 38 years: The available volume of the upper water masses changes during the first 6 years, but remains quasi-stable afterward.

On this 6-year timescale, subducted SPMW loses about $8 \%$ of its climatological volume, but its modal character is intensified. The volume of NACW (its source) increases in the same proportion, suggesting that the SPMW subduction rate is slightly underestimated by the model, and is then advected north of $50^{\circ} \mathrm{N}$ and cooled to form "unsubducted" SPMW. Part of this abundant SPMW seems to mix with denser Labrador Sea Water (LSW) in the vicinity of the Rockall Plateau, which may explain another feature of Figure 6, that is the increase in volume of the Eastern North Atlantic Water (ENAW, $\sigma_{0}>27.4$ ) [see Harvey, 1982] created by this mixing.

Once the 6-year mixed layer adjustment was achieved, it was observed that the mean quantities of the main water masses, namely NACW and subducted SPMW, had changed by about $10 \%$. With weakly constrained, extensive open boundaries, such a stabilization close to the initial state is a good result.

4.2.3. Long-term adjustment. The plots at the left in Figure 7 show that basin-averaged temperature, salinity, and kinetic energy evolve over a longer timescale, and reach a remarkably stable situation by year 35. The thermal drift also tends to zero within individual regions, such as in the four complementary boxes separated by the depth $1000 \mathrm{~m}$ and the latitude $50^{\circ} \mathrm{N}$ (plots in the middle of Figure 7). This timescale $T \sim 35$ years can be explained by different processes: 
1. Slow baroclinic Rossby waves can take centuries (in weakly stratified subpolar regions) to adjust the ocean stratification to the mean forcing. Since the initial RLM stratification is realistic, and since the relatively high horizontal diffusion may damp such slow waves, only a residual adjustment is expected. This adjustment can be achieved by first-mode long baroclinic Rossby waves for which the traveling time $T_{w}$ across the eastern basin was crudely estimated at different latitudes $y$ by $T_{w}(y) \sim L /\left(\beta a(y)^{2}\right)[P e d-$ losky, 1987]. Given the basin width $L(y)$, the Coriolis parameter gradient $\beta$, and the internal deformation radius $a(y)$, taken from Emery et al. [1984], $T_{w}$ varies from 5 to 35 years between $35^{\circ} \mathrm{N}$ and $60^{\circ} \mathrm{N}$. This is coherent with the model adjustment timescale.

2. Near the open boundaries, the total velocity field reaches quite a realistic state within 1 week (section 4.2.1). The lateral sources of tracers are therefore quickly reinitialized, and this change can affect the initial inner stratification on a timescale $T_{a}$ via advection throughout the domain. $T_{a}$ is estimated as $L / u$, where $L$ is a typical distance covered by particles around the subtropical and subpolar gyres at velocity $u$. $T_{a}$ is about $4000 \mathrm{~km} / 1 \mathrm{~cm} \mathrm{~s}^{-1} \sim 13$ years at 1000 $\mathrm{m}$, and about $3000 \mathrm{~km} / 5 \mathrm{~mm} \mathrm{~s}^{-1} \sim 20$ years at 3000 $\mathrm{m}$. These values are also compatible with $T$.

3 . The salinity gradient surrounding the Mediterranean Water (MW) tongue in RLM climatology is partly eroded after 38 years, despite the salinity source imposed at Gibraltar. In the RLM climatology, indeed, $[S,|\nabla S|]$ (in $\left[\mathrm{psu}, \mathrm{psu} \mathrm{m}^{-1}\right]$, where psu denotes practical salinity units) is about $\left[35.5,9 \times 10^{-7}\right]$ around the MW salinity maximum and $[34.9,0]$ in the southern Irminger Sea, which is $1000 \mathrm{~km}$ away. As the horizontal Laplacian diffusion coefficient is about $700 \mathrm{~m}^{2} \mathrm{~s}^{-1}$ in this area, the initial salinity gradient may be eroded within $T_{h z} \sim 27$ years. This timescale is again compatible with $T$. Vertical diffusion of the thermocline also acts over a 30-year timescale, but the good stability of the vertical density gradient throughout the simulation shows that this erosion is compensated for by other processes such as vertical advection and surface buoyancy fluxes.

To summarize, processes with very different timescales are involved in the adjustment of the model solution; this adjustement does not seem to be perturbed by the presence of the open boundaries. Despite the weak lateral constraints, stable stratification and circulation are obtained at year 38. A brief description of the final solution is presented below by way of introduction to the last section.

\subsection{Mean Circulation in the Reference Simulation}

Figure 8 presents the barotropic stream function (Figure 8a), and the velocity vectors at $72 \mathrm{~m}$ (Figure 8b), $1000 \mathrm{~m}$ (Figure 8c), and $2500 \mathrm{~m}$ (Figure 8d) after 38 years in the reference simulation. Without any direct constraint on total velocities along the open boundaries ( $\psi$ is free between its fixed values on land), the model generates a 40.5-Sv NAC above the MAR which splits into branches. The Azores Current, rarely simulated by models especially at this coarse resolution, is well reproduced; its transport above 800 $\mathrm{m}$ decreases eastward from 9 to $3 \mathrm{~Sv}$ along $33^{\circ} \mathrm{N}$. A 14-Sv Irminger Current crosses the western boundary between $52^{\circ} \mathrm{N}$ and $62^{\circ} \mathrm{N}$, recirculates cyclonically west of about $30^{\circ} \mathrm{W}$ and joins the East Greenland Current, the transport of which is increased up to 41.8 Sv. The velocity field has a strong barotropic component in the subpolar gyre and along the NAC west of $28^{\circ} \mathrm{W}$; east of about $20^{\circ} \mathrm{W}$ the upper (respectively, lower) water masses advected by the NAC north of $45^{\circ} \mathrm{N}$ (respectively, south of $55^{\circ} \mathrm{N}$ ) steer northward (respectively, southward) and join the subpolar (respectively, subtropical) gyre. South of $50^{\circ} \mathrm{N}$, in the more stratified subtropical region, the horizontal circulation varies with depth.

Comparison with literature reveals that the circulation in the model solution is quite realistic above about $2500 \mathrm{~m}$, but less satisfactory in the deepest layers: Because of deficiencies within the domain, not in the open boundary algorithm, no westward bottom flow is found in the Charlie Gibbs Fracture Zone, and the subtropical bottom circulation is reversed and distorts $\psi$ along Portugal. A detailed description and validation of the mean circulation, explanations for the origin of the modeled Azores Current, and an analysis of the intergyre dynamics will be given in a future paper.

\section{Impact of the Lateral Constraints on the Interior Solution}

The prescription of the net mass fluxes is the only constraint imposed on $\psi$ at the open boundaries, but the intensities of these integrated through flows are questionable because very few in situ data are available to support them. The intensities of the three loops depicted in Figure 2 were changed independently, and within a realistic interval around their a priori estimates. This is a way to quantify the robustness of the model solution and to learn about the 
dynamics of the basin. These tests also justify our choice of the net mass fluxes in the reference simulation.

First of all, the intensity of the northeastern loop was found to leave the eastern North Atlantic circulation unchanged: Forcing 0,2 , or $4 \mathrm{~Sv}$ around the northeastern corner only modifies the model solution north of the Iceland-Scotland Ridge (ISR). Hence the a priori estimate of $2 \mathrm{~Sv}$ was kept for the reference simulation.

In our model, indeed, the ISR introduces a $f / H$ barrier that decorrelates the circulations confined within the Norwegian Sea and within the Atlantic Ocean; the exchanges between both basins are not dependent on the northeastern loop, but on what we called the "subpolar loop". We now focus on the intensity of this loop, and of the "subtropical loop" that controls the mass exchange between the basin and the rest of the Atlantic.

\subsection{Changing the Subtropical Loop Intensity}

In addition to the reference run, here named S15 since the subtropical loop intensity $I_{\text {SUBTROP }}$ was set to $15 \mathrm{~Sv}$, two simulations S20 and S10 were made with $I_{\text {SUBTROP }}=20 \mathrm{~Sv}$ and $10 \mathrm{~Sv}$, respectively (see Table $3)$. The intensity $I_{\text {SUBPOL }}$ of the cyclonic subpolar loop was kept equal to $9 \mathrm{~Sv}$, and both simulations gave stable solutions. We hereafter refer to annual means (denoted by overbars) computed on the eighth year.

$\mathrm{S} 15, \mathrm{~S} 10$, and S20 differ mainly in the barotropic mode; the differences $\bar{\psi}_{S 20}-\bar{\psi}_{S 15}$ and $\bar{\psi}_{S 10}-\bar{\psi}_{S 15}$ are confined within a two-grid-point-thick boundary layer around the southwestern artificial island. When $I_{\text {SUBTROP }}$ is increased by $5 \mathrm{~Sv}$, the model evacuates this excess of volume within this thin anticyclonic boundary layer, without any significant impact on the rest of the basin. Similarly, when $I_{\text {SUBTROP }}$ is decreased by $5 \mathrm{~Sv}$ the model solution remains unchanged except within this boundary layer, where a thin $5-\mathrm{Sv}$ cyclonic circulation anomaly emerges to match the prescribed $I_{\text {SUBTROP }}$.

Thus a change of $+/-5 \mathrm{~Sv}$ in $I_{\text {SUBTROP }}$ does not affect the structure and transports of the NAC, the subpolar gyre, or the intergyre zone circulation. This result is remarkable, given the extensive opening of the configuration to the rest of the Atlantic. Since no "suspect" thin boundary layer was observed in S15 around the southwestern corner, suggesting that 15 $\mathrm{Sv}$ is the best estimate for $I_{\mathrm{SUBTROP}}$ with respect to the interior dynamics, $15 \mathrm{~Sv}$ was chosen as the reference value for $I_{\text {SUBTROP }}$.

The dynamical processes evoked in section 4 propagate the interior forcings (wind stress, bottom currents/topography interactions) westward across the ba-sin, along the southern boundary and toward the western boundary. The values of $\psi$ are adjusted along these open boundaries by the model dynamics with almost no influence of the prescribed net through flows. The model solution thus appears to be far more dependent on the interior dynamics and forcings (unchanged in these sensitivity experiments) than on the exchanges imposed between the basin and the rest of the Atlantic: $I_{\text {SUBTROP }}$ is not a crucial parameter, and can be tuned empirically.

\subsection{Changing the Subpolar Loop Intensity}

The subpolar loop intensity $I_{\text {SUBPOL }}$ was modified by $+/-50 \%$ around Worthington's estimate (see Table 3), without changing the other parameters. Three 20-year simulations, referred to as S3, S6, and S9 (the number corresponds to $I_{\mathrm{SUBPOL}}$ in each of them), are therefore available to evaluate the impact of a $3-\mathrm{Sv}$ decrease in $I_{\mathrm{SUBPOL}}$ on the interior solution. This impact may be investigated either from the difference between S6 and S9, or from the difference between S3 and S6. Indeed, the spatial structure, the temporal evolution, and the dynamical features are similar in both comparisons. The next section describes how simulations S6 and S9 diverge from each other, after which a dynamical interpretation of the model behavior is proposed.

5.2.1. Description of the model response. Let $\Delta(\phi)$ denote $\phi_{S 6}-\phi_{S 9}$ for any field $\phi$; let $T_{\text {ISOW }}$ (respectively, $T_{\mathrm{NACW}}$ ) be the annual mean of the eastward transport of water denser (respectively, lighter) than $\sigma_{0}=27.8$ between Iceland and Scotland, across the Iceland-Scotland Ridge (ISR). The upper plots of Figure 9 show that in $\mathrm{S} 6$ and $\mathrm{S} 9, T_{\mathrm{ISOW}}$ and $T_{\mathrm{NACW}}$ need about 10 years to adjust to the prescribed $I_{\mathrm{SUBPOL}}$. The difference S9 - S6 (lower plots of Figure 9$)$ show that both $\Delta\left(T_{\mathrm{NACW}}\right)$ and $\Delta\left(T_{\mathrm{ISOW}}\right)$ reach $-1.5 \mathrm{~Sv}$ in response to $\Delta\left(I_{\mathrm{SUBPOL}}\right)=-3 \mathrm{~Sv}$ : The eastward surface transport weakens, the deep overflow strengthens. These differences appear quasiinstantaneously and persist, despite fluctuations due to either natural causes (baroclinic transport oscillations) or artificial causes (aliasing of fast topographic waves). Simulation S9 $\left(I_{\mathrm{SUBPOL}}=9 \mathrm{~Sv}, I_{\mathrm{SUBTROP}}=15\right.$ $\mathrm{Sv}$ ) was chosen as the reference simulation because its mean overall circulation and ISOW overflow of about 
$3.5 \mathrm{~Sv}$ compare well with in situ data $(2.7 \mathrm{~Sv}$ according to Dickson and Brown [1994]) after adjustment.

Figure 10 shows $\Delta(\bar{T})$, the temperature difference along the ocean bottom, at years $1,3,7$, and 19. At $20^{\circ} \mathrm{W}$ along the Icelandic southern shelf, the overflow intensification induces a temperature decrease within the tongue of ISOW. This anomaly reaches $-0.6^{\circ} \mathrm{C}$ by year 3 and stabilizes around $-0.3^{\circ} \mathrm{C}$. A similar process occurs in the Rockall Trough (another path of the ISOW) and on the Rockall Plateau. These anomalies reach a stable state by year 10 , and remain confined to the vicinity of these topographic structures.

Initially, $\psi_{S 9}$ and $\psi_{S 6}$ differ on Iceland and on the northeastern artificial island; this difference in the lateral conditions instantaneously appears on $\psi$. Fast barotropic waves align this barotropic anomaly with $f / H$ contours within a few days, as quickly as $T_{\mathrm{NACW}}$ and $T_{\text {ISOW }}$ change; the resulting $\psi$ anomaly, due only to the constant difference between $\psi_{S 9}$ and $\psi_{S 6}$ along the northern boundary, remains the same throughout the years. To highlight the subsequent, slow baroclinic dynamical response of the model, this $\Delta(\psi)$ structure was evaluated at day 73 (the baroclinic response had not modified $\psi$ yet) and removed from the annual averages of $\Delta(\psi)$. The resulting $\Delta(\bar{\psi})$ are shown in Figure 11 for years 1, 3, 7, and 19.

A negative (cyclonic) $\psi$ anomaly between S6 and S9 progressively increases from year 1 to year 7 . Like $\Delta(\bar{T}), \Delta(\bar{\psi})$ is confined to the vicinity of the ISR during year 1 , and then slowly spreads along southern Iceland and into the Rockall Trough, "pumping" part of the NAC into this channel. Unlike $\Delta(\bar{T}), \Delta(\bar{\psi})$ then propagates westward up to the Charlie Gibbs Fracture Zone: The course of the NAC steers slightly eastward above the MAR, feeding the Iceland Basin and the Rockall Trough more, and the Irminger Sea less. This dynamical anomaly stabilizes by year 10 .

5.2.2. A dynamical interpretation. In an independent sensitivity experiment [Penduff, 1998] the overflow intensity was directly changed by modifying the Faroe Bank Channel depth. The model response was qualitatively similar to that reported above, with similar timescales. Therefore the cold anomaly between S6 and S9 which slowly spreads downstream of the ISR, and its dynamical consequences, are undoubtedly triggered by the change in $T_{\text {ISOW }}$.

The thermal wind equation links the negative signs of $\Delta(\bar{\psi})$ and $\Delta(\bar{T})$ south of Iceland: The stronger cross-shore density gradient in run S6 (observed over most of the water column) is geostrophically coherent with the stronger westward current and the intensi- fied cyclonic circulation in the Iceland Basin. Both $T$ and $\psi$ anomalies remain strongly correlated during the first 3 years of their slow spatial expansion.

The baroclinic driving of this barotropic anomaly is confirmed by locating the modifications of the JEBAR term (equation (1)). As explained by Mertz and Wright [1992], JEBAR diagnoses a cross- $f / H$ barotropic flow due to density stratification. Among all the contributions (wind stress, nonlinearities, bottom friction, etc.) able to generate cross- $f / H$ barotropic flows in our model, JEBAR was shown to be clearly dominant in the subpolar gyre.

Figure 12 presents successive plots of $\Delta(\overline{\text { JEBAR }})$. As expected from equation (1), the behavior of this term (emergence near the overflow region, slow westward and southward spreading, confinement near the topography) is close to that of $\Delta(\bar{T}) . \Delta(\overline{\mathrm{JEBAR}})$ localizes the regions where the stratification modifications induce changes in cross- $f / H$ flows. Since $\psi$ is nondivergent, the along- $f / H$ flow is also expected to be modified in those regions and to adjust quickly along the $f / H$ contours toward southern Greenland (see Figure 4). Indeed, during the first 3 years, $\psi$ differs between S6 and S9 wherever JEBAR does, and also downstream along southern Iceland.

Contrary to $\Delta(\bar{T})$ and $\Delta(\overline{\text { JEBAR }})$, the $\psi$ anomaly spreads toward the subpolar basin interior between year 3 and year 10. In particular, the slight change in direction of the NAC above the MAR is not associated with any local change in the stratification. This dynamical signal seems to be forced near the ISR and to propagate upstream along the $f / H$ contours that connect the MAR region with the Rockall Trough.

As reported by Redler and Böning [1997] and Roberts and Wood [1997] with different models (geopotential vertical coordinates, domain including the entire subpolar gyre, different resolutions and forcings), the ISOW overflow intensity, controlled here by $I_{\text {SUBPOL }}$, has an effect on the stratification in the Iceland Basin, the steering of the NAC above the MAR, and the circulation in the subpolar gyre. The western half of the subpolar gyre is not needed for these processes to take place, since they are linked with the water exchange across the ISR (as already stated by Redler and Böning [1997]). Our results show that this effect is mostly driven by a deep baroclinic signal that slowly propagates into the Atlantic and progressively affects the NAC path up to the MAR. Whether such a dynamical link exists in the real ocean is an interesting issue. It is plausible but difficult to verify given the uncertainties about the transport and direction of 
the real NAC in historical time series.

\section{Conclusion}

The SPEM5.1 primitive equation model was implemented on a regional configuration of the eastern North Atlantic, extending from $40^{\circ} \mathrm{W}$ to $0.8^{\circ} \mathrm{W}$, and from $30^{\circ} \mathrm{N}$ to $66.5^{\circ} \mathrm{N}$. Except along the northern limit where the model variables had to be prescribed, the domain is surrounded by original selfadapting open boundary conditions. The treatment of baroclinic variables is similar to that presented by Barnier et al. [1998] and Marchesiello et al. [1998], and the net transports across each boundary are still prescribed. However, unlike in previous model studies, the barotropic stream function $\psi$ is free all along the open boundaries to adjust to the inner dynamics and forcings, even in the event of inflow: No relaxation of $\psi$ to any a priori estimate is needed. The feedback of the inner dynamics on the outer ocean is therefore taken into account through the lateral forcing.

Fast geostrophic and barotropic adjustment processes reshape the unrealistic initial velocity field to balance the barotropic vorticity equation. During the first 6 years the main water masses of the mixed layer (NACW, SPMW) and the subducted SPMW adjust to the surface forcings; the individual volumes of these water masses change by about $10 \%$ during the first 6 years and stabilize thereafter. The simulation is stopped after 38 years of integration, when slower processes have adjusted the full-depth stratification. In spite of the size of the open boundaries and the weak lateral constraints, the final state is stable. The main features of the model solution (in particular, the paths and transports of the North Atlantic Current and of the Azores Current) appear quite realistic.

Are the net mass transports prescribed across the boundaries crucial parameters in this configuration? Sensitivity experiments showed that the velocity field along the domain perimeter and inside it hardly depend on the integrated mass flux forced between the regional model and the Atlantic through the western and southern boundaries. Along both these boundaries, velocities are adjusted to the interior dynamics by westward propagating processes. The wide opening of this configuration to the rest of the Atlantic does not seem to adversely affect the solution.

On the other hand, the integrated circulation forced around Iceland has a significant influence on the subpolar dynamics and on the NAC path. Decreasing this transport immediately strengthens the intensity of the dense overflow between Iceland and Scotland, and, within a couple of years, a cold anomaly is advected along the paths of this overflow which locally intensifies the cyclonic circulation in the Icelandic basin and around the Rockall Plateau. A slow westward propagating signal reaches the Charlie Gibbs Fracture Zone after about 10 years: The NAC steers slightly eastward above the Mid-Atlantic Ridge and intensifies the eastern subpolar circulation. This dynamical effect, already reported by Redler and Böning [1997], has a baroclinic origin, controlled by the intensity of the ISOW overflow via the stratification.

The open boundaries proved their self-adaptability along the extensive western and southern limits of the domain: Here, the lateral profile of $\psi$ is naturally adjusted to the interior dynamics since Rossby waves bring information toward the boundaries. Such extensive open boundaries would probably be less effective along the eastern limit of regional domains, because barotropic waves do not propagate toward it. Here, the control of the barotropic mode via a relaxation term (as used by Marchesiello et al. [1998]) seems necessary. Indeed, our eastern open boundary did not adjust as properly as the other ones to the interior circulation, but its influence on the basin circulation was small.

By relaxing an important dynamical constraint around the domain, this approach provides an alternative to nonlinear inversions (see Paillet and Mercier [1997], for instance) for diagnosing regional circulation schemes, coherent with a climatological stratification and surface forcings. In addition, the present model explicitly solves the fluctuating processes, in particular the mutual adjustment of the stratification, circulation, and forcing. The general circulation and the intergyre model dynamics will be analyzed in a forthcoming paper. The model is currently being implemented at high resolution for a study of the basin turbulence.

Acknowledgments. This research was supported by a DRET doctoral fellowship for 3 years, and by a SHOM research contract for the fourth year. We would like to thank Rene Redler and an anonymous reviewer whose thorough work contributed to a real improvement of the paper.

\section{References}

Arhan, M., A. Colin de Verdiere, and L. Memery, The eastern boundary of the subtropical North Atlantic, $J$. 
Phys. Oceanogr., 24, 1295-1316, 1994.

Barnier, B., L. Siefridt, and P. Marchesiello, Thermal forcing for a global ocean circulation model using a threeyear climatology of ECMWF analyses, J. Mar. Syst., 6, 363-380, 1995.

Barnier, B., P. Marchesiello, A.P. de Miranda, J.M. Molines, and M. Coulibaly, A sigma-coordinate primitive equation model for studying the circulation in the South Atlantic, I, Model configuration with error estimates, Deep Sea Res., 45, 573-608, 1998.

Blumberg, A.F., and L.H. Kantha, Open boundary condition for circulation models, J. of Hydraul. Eng., 111, 237-255, 1985.

Böning, C.W., F.O. Bryan, W.R. Holland, and R. Döscher, Deep-water formation and meridional overturning in a high-resolution model of the North Atlantic, J. Phys. Oceanogr., 26, 1142-1164, 1996.

Bryan, F.O., and W.R. Holland, A high resolution simulation of the wind- and thermohaline-driven circulation in the North Atlantic Ocean, in Parametrization of Small Scale Processes: 'Aha Huliko'a Hawaiian Winter Workshop, edited by P. Müller and D. Henderson, pp. 99-115, Hawaii Inst. Geophys., Honolulu, 1989.

Bryan, F.O., C.W. Böning, and W.R. Holland, On the nidlatitude circulation in a high-resolution model of the North Atlantic, J. Phys. Oceanogr., 25, 289-305, 1995.

de Miranda, A.P., B. Barnier, and W.K. Dewar, Mode waters and subduction rates in a high-resolution South Atlantic simulation, J. Mar. Res., 57, 213-244, 1999.

Dickson, R.R., and J. Brown, The production of North Atlantic Deep Water: Sources, rates, and pathways, $J$. Geophys. Res., 99, 12,319-12,341, 1994.

Dietrich, G., K. Dalle, W. Krauss, and G. Siedler, Allegemeine Meereskunde, 593 pp., Bornträger, Berlin, 1975.

Döscher, R., and R. Redler, The relative importance of northern overflow and subpolar deep convection for the North Atlantic thermohaline circulation, J. Phys. Oceano-gr., 27, 1894-1902, 1997.

DYNAMO Group, DYNAMO, Dynamics of North Atlantic Models: Simulation and Assimilation with High Resolution Models, 334 pp., Inst. für Meereskunde, Kiel, Germany, 1997.

Emery, W.J., W.G. Lee, and L.Magaard, Geographic and seasonal distributions of Brünt-Väisälä frequency and Ro-ssby radii in the North Pacific and North Atlantic, J. Phys. Oceanogr., 14, 294-317, 1984.

Haidvogel, D.B., J.L. Wilkin, and R. Young, A semispectral primitive equation ocean circulation model using vertical sigma and orthogonal curvilinear horizontal coordinates, J. Comput. Phys., 94, 151-185, 1991.

Harvey, J., $\theta$-S relationship and watermasses in the eastern North Atlantic, Deep Sea Res., 29, 1021-1033, 1982.

Hellermann, S., and M. Rosenstein, Normal monthly wind stress on the world ocean with error estimates, J. Phys. Oceanogr., 13, 1093-1104, 1983.

Krauss, W., The North Atlantic Current, J. Geophys.
Res., 91, 5061-5074, 1986.

Marchesiello, P., Simulation de la circulation océanique dans l'Atlantique Sud, avec un modèle à coordonnées sigma, thèse, Univ. J. Fourier, 191 pp., Grenoble, France, April 1995.

Marchesiello, P., B. Barnier, and A.P de Miranda, A sigma-coordinate primitive equation model for studying the circulation in the South Atlantic, II, Meridional transports and seasonal variability, Deep Sea Res., 45, 543-572, 1998.

Mercier, H., M. Ollitrault, and P.Y. Le Traon, An inverse model of the North Atlantic general circulation using lagrangian float data, J. Phys. Oceanogr., 23, 689-715, 1993.

Mertz, G., and D.W. Wright, Interpretations of JEBAR term, J. Phys. Oceanogr., 22, 301-305, 1992.

Orlanski, I., A simple boundary condition for unbounded hyperbolic flows, J. Comput. Phys., 21, 251-269, 1976.

Paillet, J., and H. Mercier, An inverse model of the eastern North Atlantic general circulation and thermocline ventilation, Deep Sea Res. I, 44, 1293-1328, 1997.

Palma, E.D., and R.P. Matano, On the implementation of passive open boundary conditions for a general circulation model: The barotropic mode, J. Geophys. Res., 103, 1319-1341, 1998.

Pedlosky, J., Geophysical Fluids Dynamics, and ed., 710 pp., Springer-Verlag, Berlin, 1987.

Penduff, T., Etude de la dynamique de l'Atlantique NordEst à l'aide d'un modèle numérique régional, thèse, Univ. de Bretagne Occidentale, 261 pp., Brest, France, Oct. 1998.

Raymond, X.H., and H.L. Kuo, A radiation boundary condition for circulation models, J. Hydraul. Eng., 111, 237-255, 1984.

Redler, R., and C.W. Böning, Effect of the overflows on the circulation in the subpolar North Atlantic: A regional model study, J. Geophys. Res., 102, 18,52918,552, 1997.

Reynaud, T., P. Legrand, and H. Mercier, A new analysis of hydrographic data in the Atlantic and its application to an inverse modelling study, WOCE Newslett., 32, 2931, Sept. 1998.

Roberts, M.J., and R.A. Wood, Topographic sensitivity studies with a Brian-Cox-type ocean model, J. Phys. Oceanogr., 27, 823-836, 1997.

Sommerfeld, A., Partial Differential Equations, Lect. Theoret. Phys., vol. 6, Academic, San Diego, Calif., 1949.

Stevens, D.P., On open boundary conditions for three dimensional primitive equation ocean circulation models, Geophys. Astrophys. Fluid Dyn., 51, 103-133, 1990.

Stevens, D.P., The open boundary condition in the United Kingdom Fine-Resolution Antarctic Model, J. Phys. Oce-anogr., 21, 1494-1499, 1991.

Stevens, I.G., and J.A. Johnson, Sensitivity to open boundary forcing in a fine-resolution model of the Iberian shelf-slope region, Ann. Geophys., 15, 113-123, 
1997.

Sy, A., Investigation of large-scale circulation patterns in the central North Atlantic: The North Atlantic Current, the Azores Current, and the Mediterranean Water plume in the area of the Mid-Atlantic Ridge, Deep Sea Res., 35, 383-413, 1988.

Worthington, L.V., The Norwegian Sea as a Mediterranean basin, Deep Sea Res., 17, 77-84, 1970.

B. Barnier and T. Penduff, Laboratoire des Écoulements Géophysiques et Industriels, UMR 5519 CNRS, BP $53 \mathrm{X}$, 38041 Grenoble Cedex, France. (Bernard.Barnier@hmg. inpg.fr; Thierry.Penduff@hmg.inpg.fr)

A. Colin de Verdière, Laboratoire de Physique des Océans, UMR 6523, Université-CNRS-IFREMER, Université de Bretagne Occidentale, Brest, France. (Alain.ColinDe-Verdiere@univ-brest.fr)

May 11, 1999; revised November 18, 1999; accepted December 6, 1999.

This preprint was prepared with AGU's LATEX macros v4. File BR1² formatted May 11, 2003. 
Figure 1. Eastern North Atlantic configuration (limits: $40^{\circ} \mathrm{W}, 0.8^{\circ} \mathrm{W}, 30^{\circ} \mathrm{N}, 66.5^{\circ} \mathrm{N}$ ), geography and topography after interpolation on the horizontal grid and smoothing; depths in $\mathrm{m}$, masked regions appear as unshaded areas inside the domain. The mean paths of the North Atlantic Current and of the Azores Current west of the domain are redrawn from $S y$ [1988].

Figure 2. Bathymetry and volume exchange across the boundaries condensed into closed loops. The numbers in the boxes indicate the individual intensity of these loops in the reference simulation.

Figure 3. The barotropic stream function $\psi$ at $t=0$. The contour interval is $2 \mathrm{~Sv}$. In this and subsequent figures of $\psi$ the shaded regions correspond to anticyclonic circulations, the unshaded regions correspond to cyclonic circulations.

Figure 4. Selected $f / H$ contours in the domain.

Figure 5. The barotropic stream function during the first two days of integration. The contour interval is $2 \mathrm{~Sv}$.

Figure 6. Equivalent thickness of the water masses (volume/domain area, in meters) in the top $1000 \mathrm{~m}$, sorted by neighboring $0.1 \mathrm{~kg} \mathrm{~m}^{-3}$-wide density classes, and diagnosed on day 73 of: (a) the first year of integration; (b) year 5; and (c) year 38. Relative change of $H_{e q}\left(\left[H_{e q}-H_{e q}(\mathrm{t}=73\right.\right.$ days $\left.)\right] / H_{e q}(\mathrm{t}=73$ days $\left.)\right)$ in percent after $(\mathrm{d}) 5$ years and (e) 38 years of integration.

Figure 7. On-line diagnostics during 38 years. The plots at the left show basin-averaged temperature, salinity, and kinetic energy. The four plots in the middle show the evolution of the mean temperature in four boxes: (clockwise from upper left) above $1000 \mathrm{~m}$ and north of $50^{\circ} \mathrm{N}$, above $1000 \mathrm{~m}$ and south of $50^{\circ} \mathrm{N}$, below $1000 \mathrm{~m}$ and south of $50^{\circ} \mathrm{N}$, and below $1000 \mathrm{~m}$ and north of $50^{\circ} \mathrm{N}$. The four latter plots are shown on the same graph at the right-hand side. The heavy lines are deduced from the light ones by smoothing the seasonal cycle.

Figure 8. Circulation averaged over year 38: (a) Barotropic stream function $\psi$, $\min =-24.3 \mathrm{~Sv}, \max =41.25$ $\mathrm{Sv}$, interval $=2 \mathrm{~Sv}$. Bathymetry (contour interval of $1000 \mathrm{~m}$ ) and velocity vectors (only one vector in every two is plotted) at (b) $72 \mathrm{~m}$, (c) $1000 \mathrm{~m}$, and (d) $2500 \mathrm{~m}$. The minimum and maximum velocities are displayed above each plot.

Figure 9. (top) Temporal evolution of $T_{\mathrm{NACW}}$ and $T_{\mathrm{ISOW}}$ across the ISR for simulations $\mathrm{S} 6$ (thin lines) and S9 (thick lines). (bottom) $\Delta\left(T_{\mathrm{NACW}}\right)$ and $\Delta\left(T_{\mathrm{ISOW}}\right)$. See the text for definitions.

Figure 10. Bottom temperature difference between simulations S6 and S9, at years 1, 3, 7, and 19. Contour interval is $0.2^{\circ} \mathrm{C}$; positive anomalies are lightly shaded, negative anomalies are heavily shaded.

Figure 11. The $\psi$ difference between simulations S6 and S9 (noted $\Delta(\bar{\psi})$ in the text) for years $1,3,7$, and 19 . Contour interval is $1 \mathrm{~Sv}$; cyclonic anomalies are lightly shaded, anticyclonic anomalies are heavily shaded.

Figure 12. JEBAR difference between simulations $\mathrm{S} 6$ and $\mathrm{S} 9$ at years $1,3,7$, and 19. This term was multiplied by $H / \beta$ ( $H$ is local depth, and $\beta$ is the Coriolis parameter gradient) to form the product of the local depth with the cross- $f / H$ barotropic velocity anomaly. Contour interval is $200 \mathrm{~m}^{2} \mathrm{~s}^{-1}$; positive anomalies are lightly shaded, negative anomalies are heavily shaded. 
Table 1. Vertical Grid: Depth $z(k)$ of the Vertical Velocity Points for Various Values of the Ocean Depth, $h$

\begin{tabular}{|c|c|c|c|c|}
\hline$\sigma$ Level Number $k$ & $z(k)$ if $h=500 \mathrm{~m}$ & $z(k)$ if $h=2920 \mathrm{~m}$ & $z(k)$ if $h=5340 \mathrm{~m}$ & Vertical Grid Step for $h=5340 \mathrm{~m}$ \\
\hline 21 & 0.00 & 0.00 & 0.00 & 0.00 \\
\hline 20 & -10.60 & -19.26 & -27.93 & 27.93 \\
\hline 19 & -21.52 & -41.47 & -61.42 & 33.49 \\
\hline 18 & -32.97 & -68.43 & -103.89 & 42.47 \\
\hline 17 & -45.22 & -102.73 & -160.23 & 56.34 \\
\hline 16 & -58.69 & -147.96 & -237.24 & 77.00 \\
\hline 15 & -73.87 & -208.81 & -343.74 & 106.50 \\
\hline 14 & -91.37 & -290.63 & -489.89 & 146.15 \\
\hline 13 & -111.70 & -398.18 & -684.66 & 194.78 \\
\hline 12 & -135.07 & -533.21 & -931.34 & 246.68 \\
\hline 11 & -161.04 & -691.83 & -1222.61 & 291.27 \\
\hline 10 & -188.52 & -864.20 & -1539.88 & 317.27 \\
\hline 9 & -216.18 & -1038.09 & -1860.00 & 320.12 \\
\hline 8 & -243.00 & -1204.51 & -2166.02 & 306.02 \\
\hline 7 & -268.78 & -1361.39 & -2454.01 & 287.99 \\
\hline 6 & -294.01 & -1513.28 & -2732.55 & 278.54 \\
\hline 5 & -319.64 & -1668.90 & -3018.16 & 285.61 \\
\hline 4 & -346.88 & -1839.04 & -3331.20 & 313.04 \\
\hline 3 & -377.02 & -2035.48 & -3693.94 & 362.74 \\
\hline 2 & -411.48 & -2271.05 & -4130.63 & 436.69 \\
\hline 1 & -451.84 & -2560.23 & -4668.61 & 537.98 \\
\hline 0 & -500.00 & -2920.02 & -5340.04 & 671.43 \\
\hline
\end{tabular}

Depths are in meters. The other variables are located halfway between these depths. 
Table 2. Treatment of the Model Variables at Every Time Step and at Every Point of the Western, Southern, and Eastern Open Boundaries

\begin{tabular}{|c|c|c|}
\hline Variables & Outflow Regime & Inflow Regime \\
\hline $\begin{array}{l}\text { Baroclinic normal velocity, } \\
\text { total tangential velocity, } \\
\text { temperature, and salinity } \\
\text { (B98 method) }\end{array}$ & $\begin{array}{l}\text { radiation of perturbations, } \\
\text { weak relaxation to } \mathrm{RLM}^{\mathrm{b}} \\
\text { climatology with } \\
\tau^{\mathrm{c}}=5 \text { years. }\end{array}$ & $\begin{array}{l}\text { NO radiation of perturbations, } \\
\text { strong relaxation to RLM } \\
\text { climatology with } \\
\tau^{\mathrm{c}}=15 \text { days for tracers, } \\
\tau^{\mathrm{c}}=3 \text { days for velocities. }\end{array}$ \\
\hline $\begin{array}{l}\text { Barotropic stream function } \\
\text { (new method) }\end{array}$ & $\begin{array}{l}\text { radiation of perturbations, } \\
\text { NO relaxation to RLM } \\
\text { climatology. }\end{array}$ & $\begin{array}{l}\text { NO radiation of perturbations, } \\
\text { NO relaxation to RLM } \\
\text { climatology } \\
\Rightarrow \psi \text { persists at this point. }\end{array}$ \\
\hline
\end{tabular}

${ }^{\text {a }}$ B98 refers to Barnier et al. [1998]'s open boundary conditions.

${ }^{\mathrm{b}} \mathrm{RLM}$ refers to Reynaud et al. [1998]'s climatology to which the tracers are relaxed; climatological values for the baroclinic normal velocity field geostrophically derive from the RLM density fields; the climatological value for the total tangential velocity field is zero.

${ }^{\mathrm{c}}$ The parameter $\tau$ denotes the relaxation timescale for the variables that are relaxed to climatology. 
Table 3. Intensity of the Large-Scale Loops Shown in Figure 2 and Net Transports Prescribed Through the Five Boundaries of the Domain

\begin{tabular}{|c|c|c|c|c|c|c|}
\hline & A Priori Value ${ }^{a}$ & Reference Simulation ${ }^{\mathrm{b}}$ & $\mathrm{S} 10^{\mathrm{c}}$ & $\mathrm{S} 20^{\mathrm{c}}$ & $\mathrm{S} 3^{\mathrm{c}}$ & $S 6^{c}$ \\
\hline \multicolumn{7}{|c|}{ Intensity of the Large-Scale Loops Shown in Figure 2, Sv } \\
\hline Subpolar loop & 6 & 9 & 9 & 9 & 3 & 6 \\
\hline Subtropical loop & 15 & 15 & 10 & 20 & 15 & 15 \\
\hline Northeastern loop & 2 & 2 & 2 & 2 & 2 & 2 \\
\hline \multicolumn{7}{|c|}{ Net Transport Prescribed Through the Five Boundaries, Sv } \\
\hline Northwestern $\mathrm{FB}^{\mathrm{d}}$ & -6 & -9 & -9 & -9 & -3 & -6 \\
\hline Northeastern $\mathrm{FB}^{\mathrm{d}}$ & -2 & -2 & -2 & -2 & -2 & -2 \\
\hline
\end{tabular}


Table 3. (continued)

\begin{tabular}{rccrrrr}
\hline & A Priori Value $^{\mathrm{a}}$ & Reference Simulation $^{\mathrm{b}}$ & $\mathrm{S}^{\mathrm{c}}$ & $\mathrm{S}^{\mathrm{c}} 0^{\mathrm{c}}$ & $\mathrm{S}^{\mathrm{c}}$ & $\mathrm{S6}^{\mathrm{c}}$ \\
\hline Eastern OB $^{\mathrm{e}}$ & 8 & 11 & 11 & 11 & 5 & 8 \\
Southern OB $^{\mathrm{e}}$ & -15 & -15 & -10 & -20 & -15 & -15 \\
Western OB $^{\mathrm{e}}$ & 15 & 15 & 10 & 20 & 15 & 15 \\
\hline
\end{tabular}

Negative values correspond to a southward or a westward transport.

${ }^{\mathrm{a}} \mathrm{A}$ priori estimates from the literature (see text).

${ }^{\mathrm{b}}$ Parameters used in the reference experiment, also named S15 and S9.

${ }^{\mathrm{c}}$ Parameters used in the sensitivity experiments (section 5).

${ }^{\mathrm{d}} \mathrm{FB}$ denotes fixed boundary.

${ }^{\mathrm{e}} \mathrm{OB}$ denotes self-adapting open boundary. 


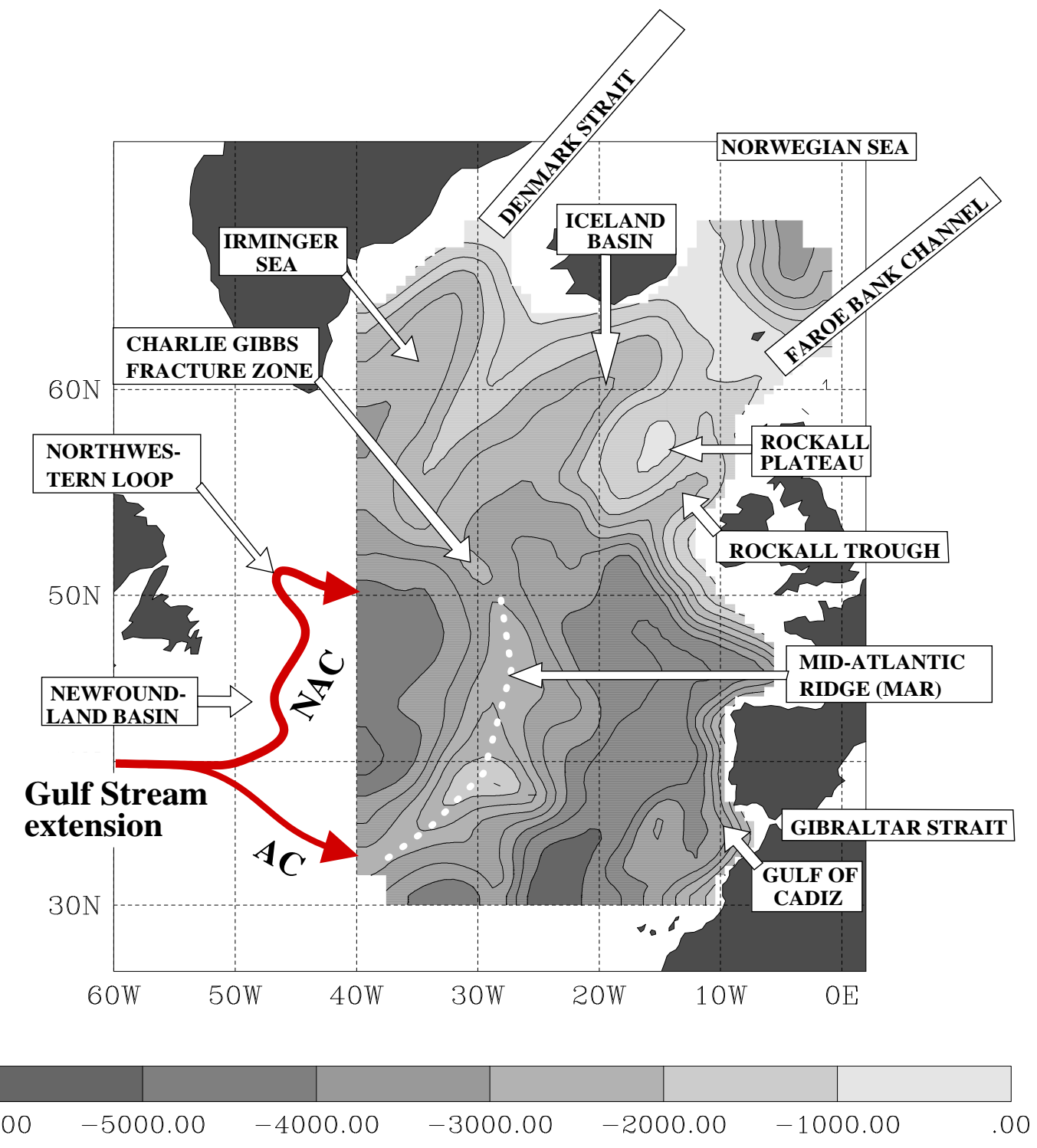

Figure 1 


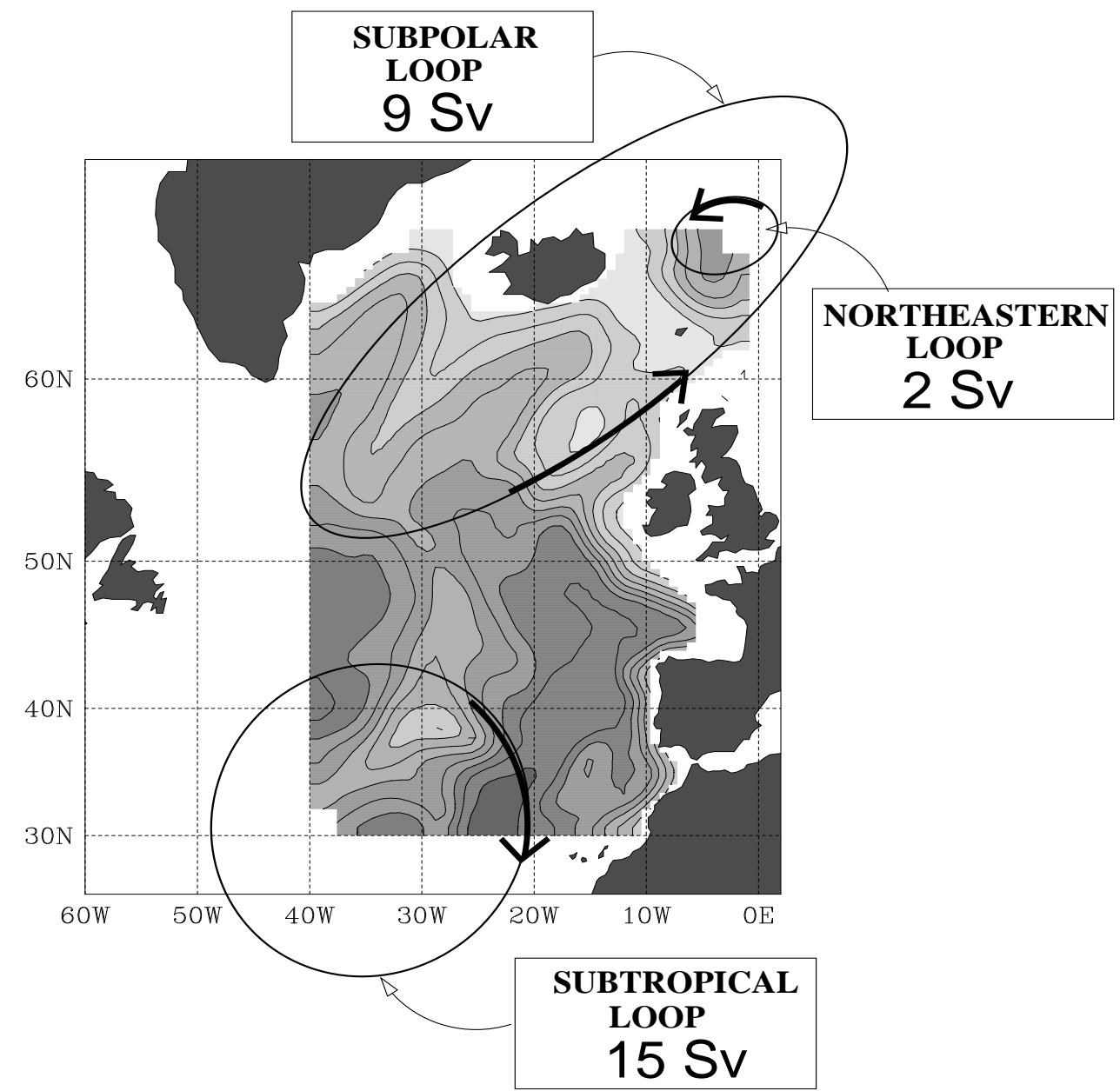

Figure 2 


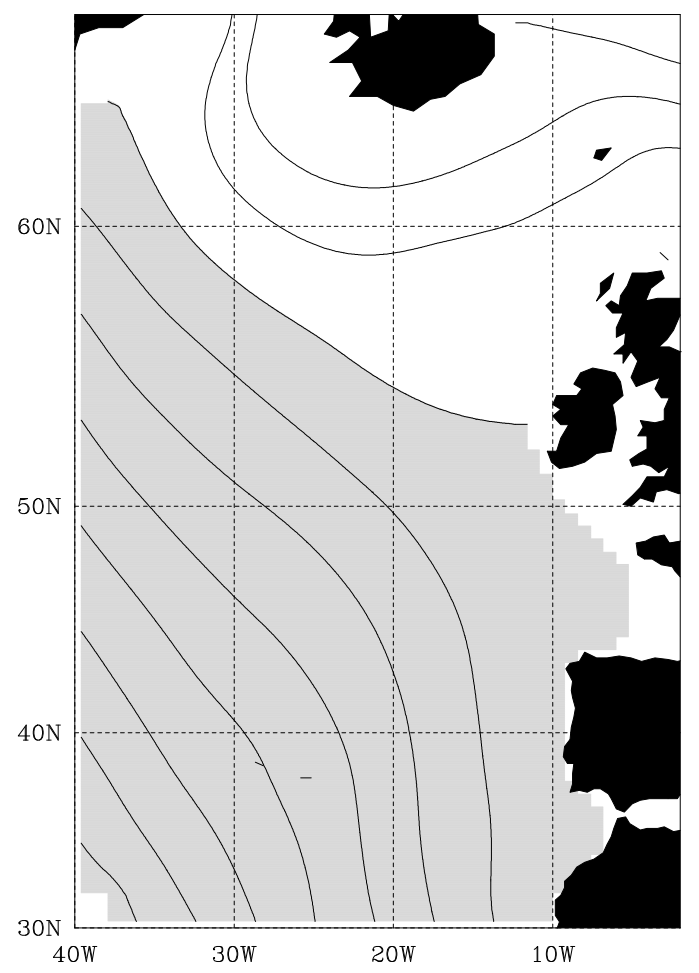

Figure 3 


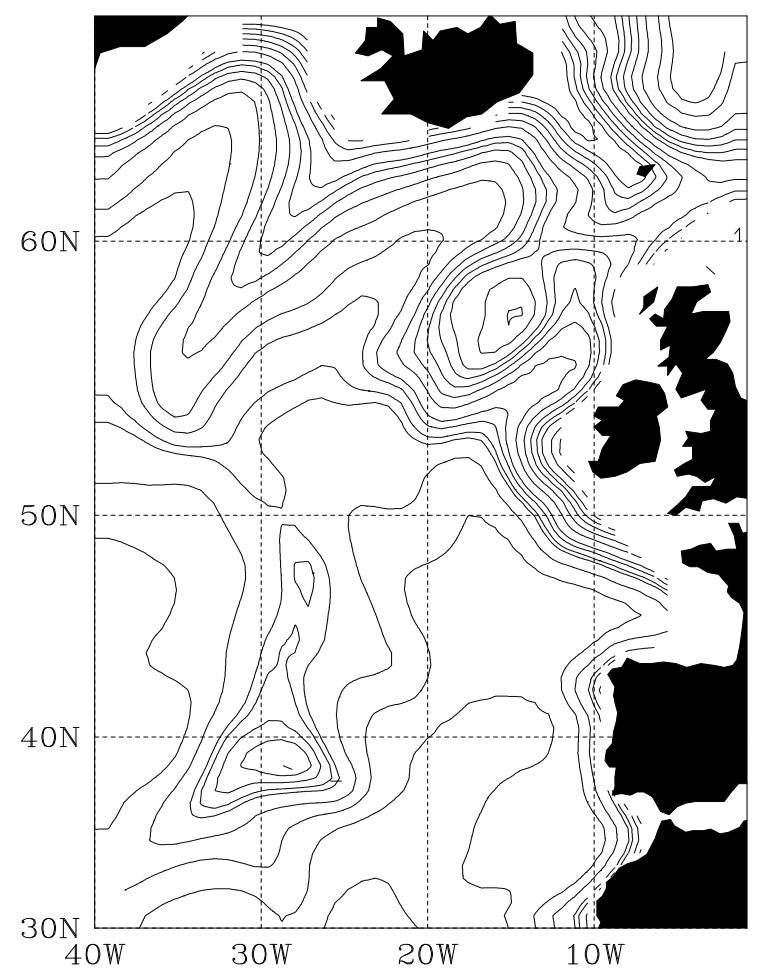

Figure 4 


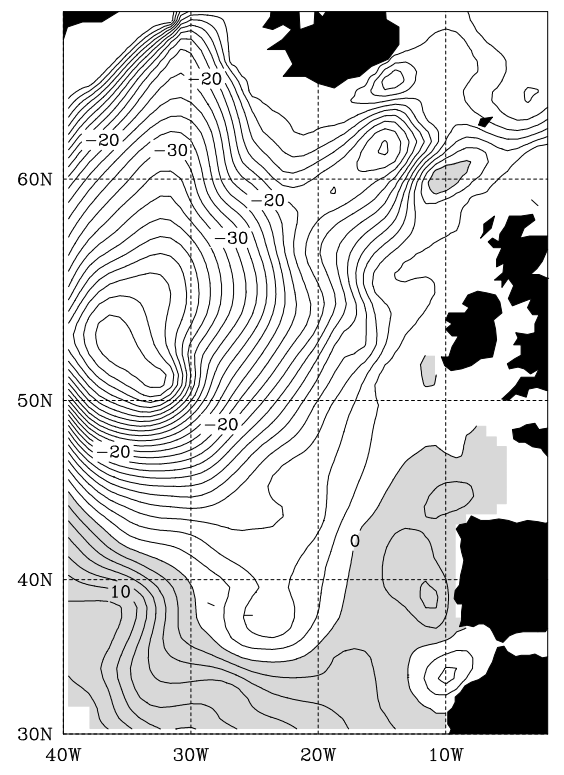

(a) $\psi$ after one day.

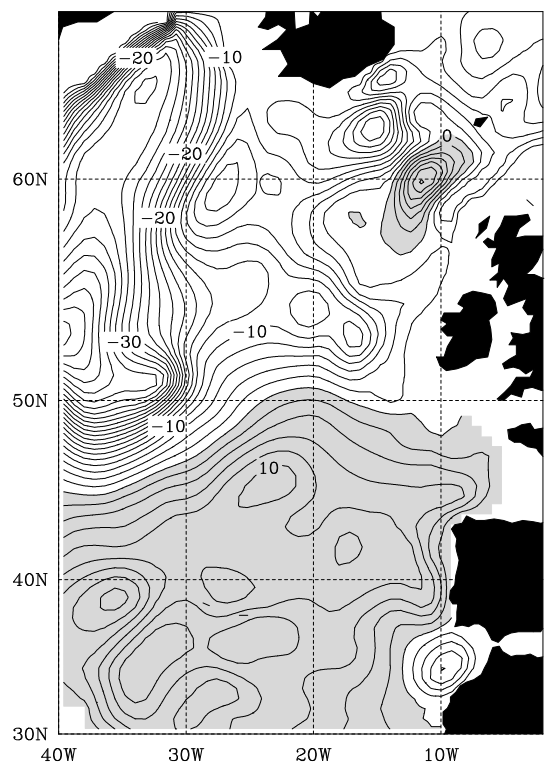

(b) $\psi$ after two days.

Figure 5 

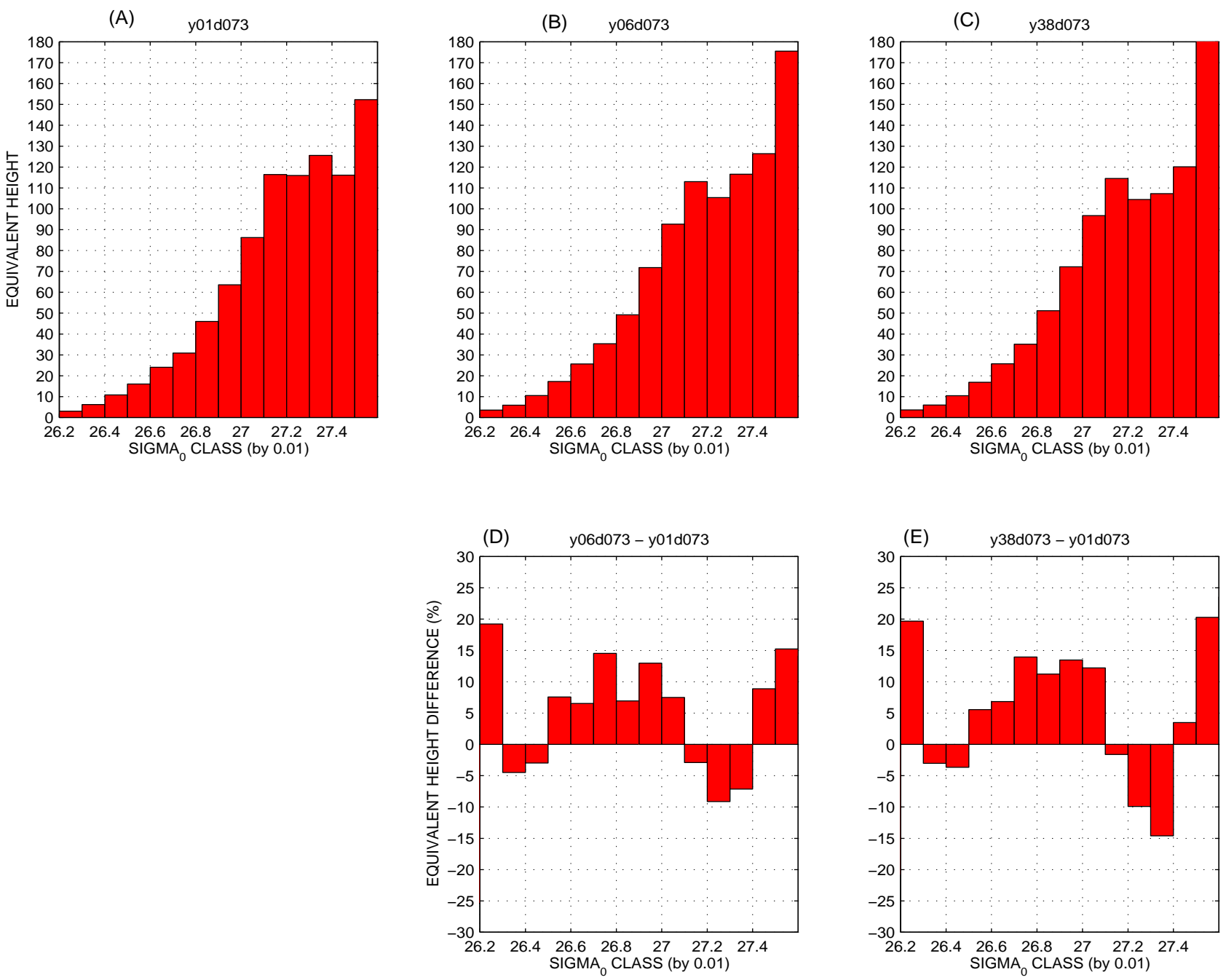

Figure 6 

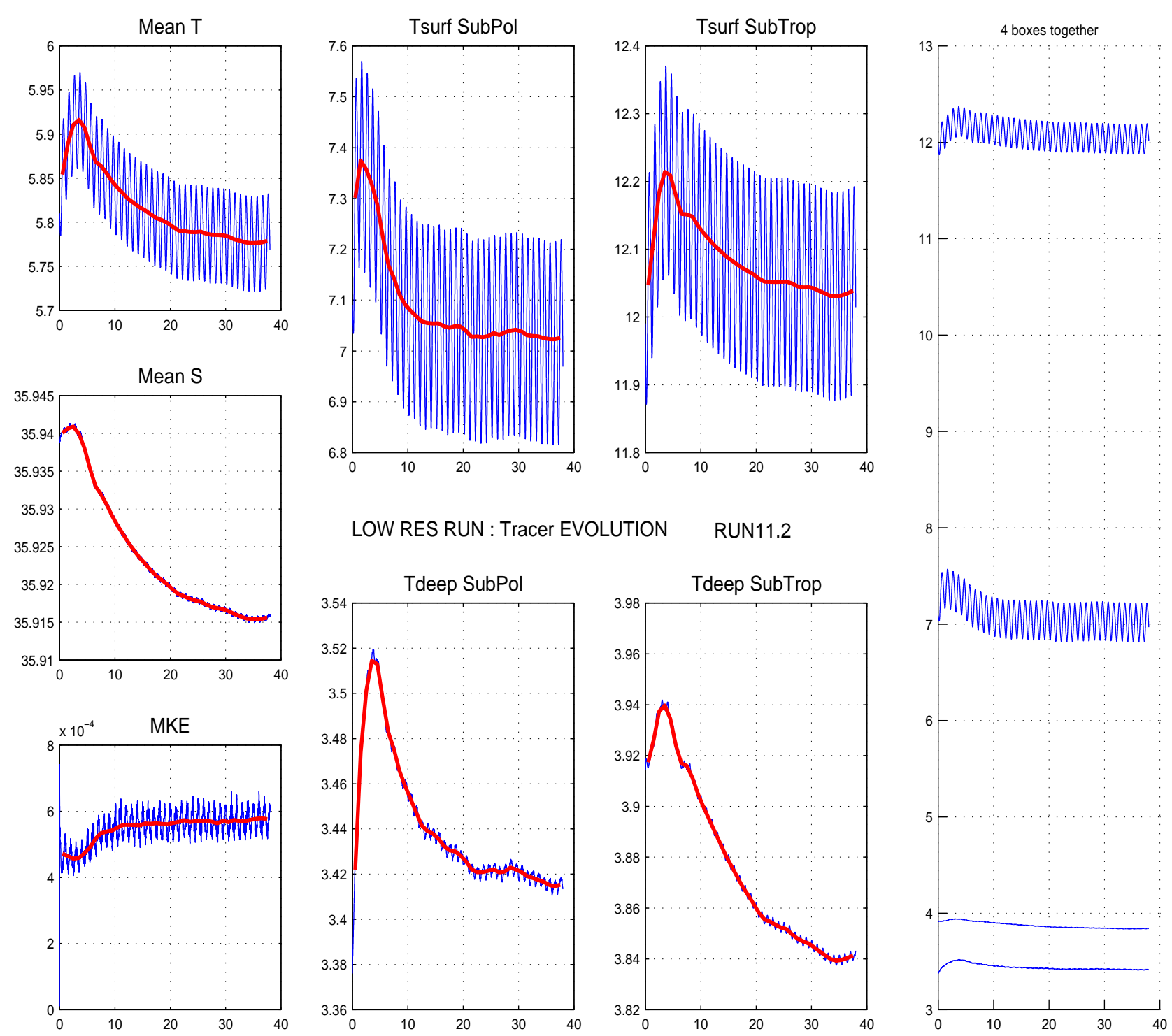

Figure 7 


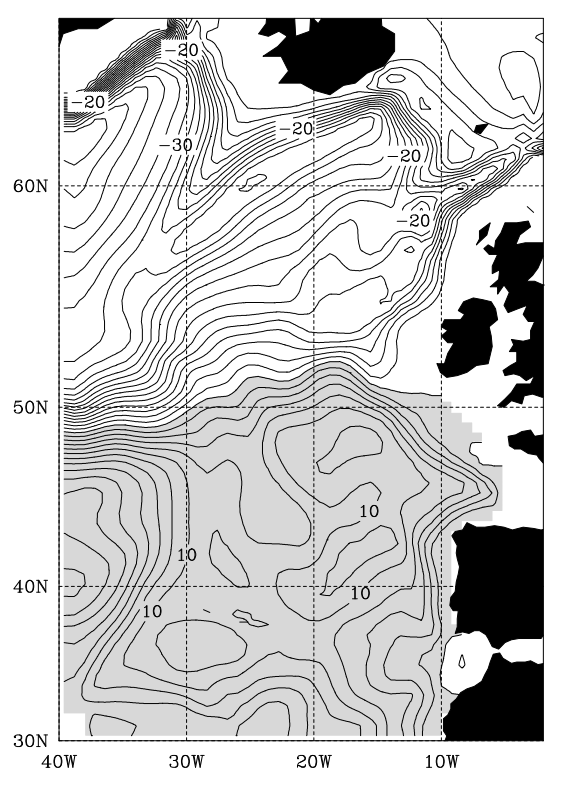

(c) : $\psi(\mathrm{Sv})$

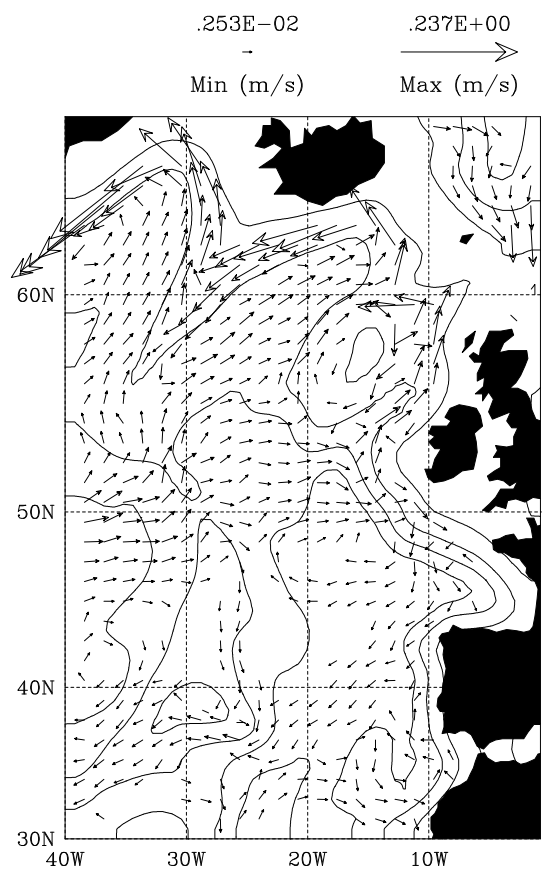

(e) : velocity at $1000 \mathrm{~m}$
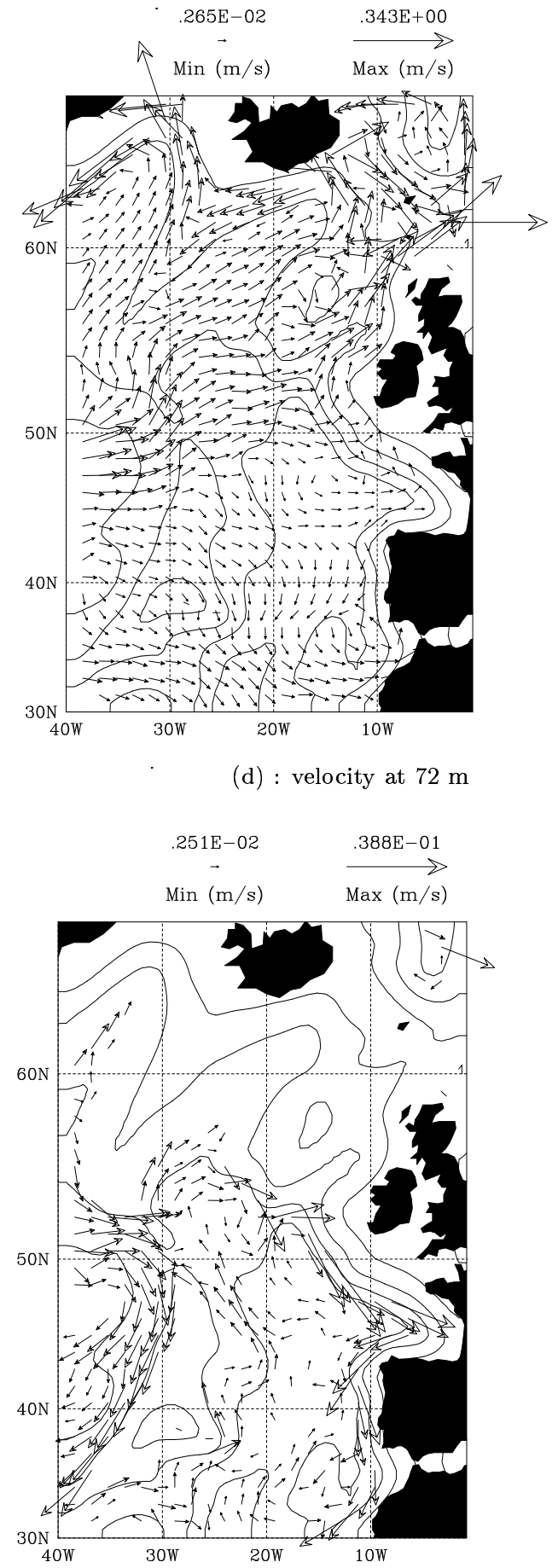

(f) : velocity at $2500 \mathrm{~m}$

Figure 8 

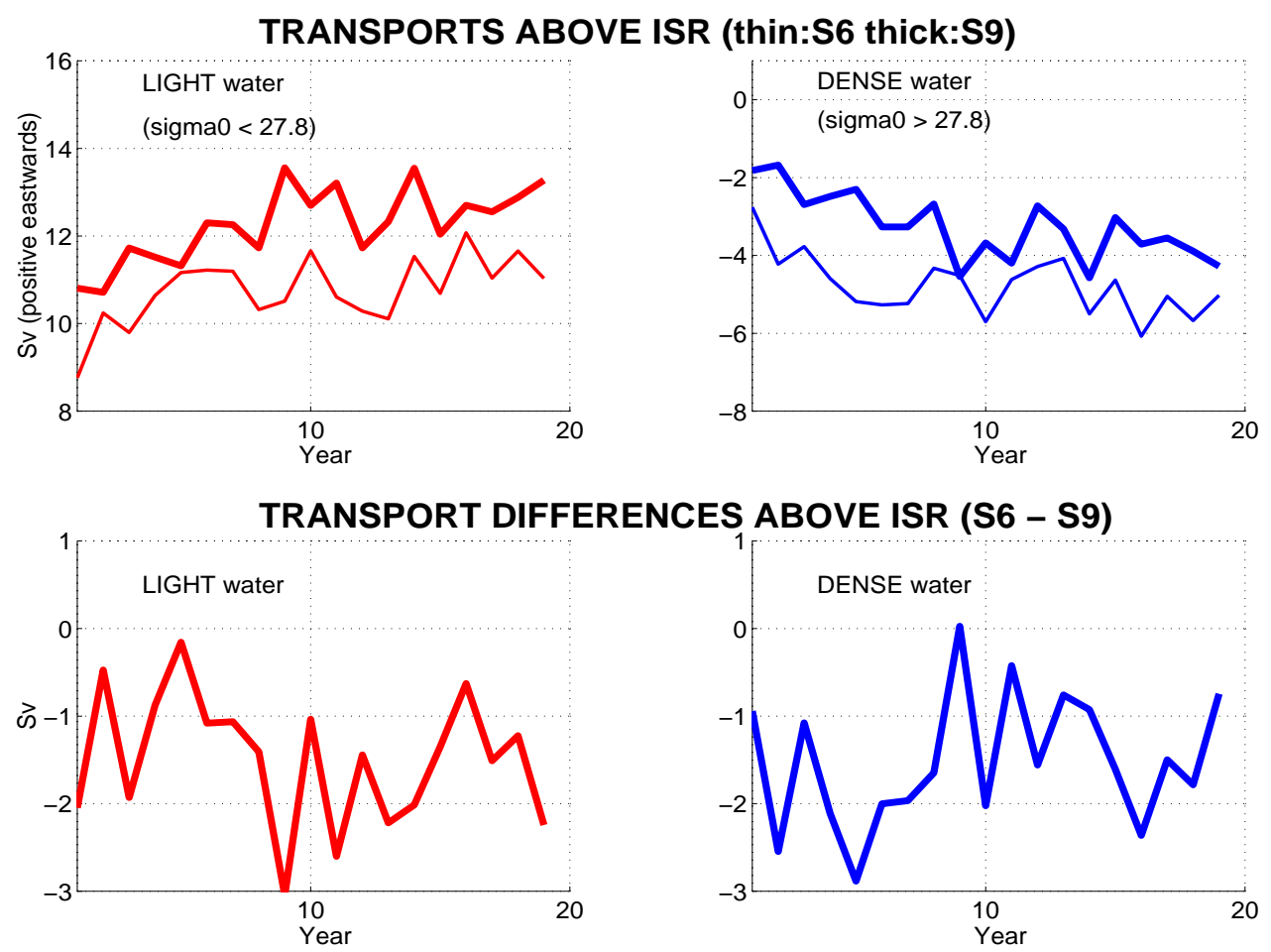

Figure 9 
$\operatorname{delta}(\mathrm{T}),[\mathrm{S} 6]-[\mathrm{S} 9]$, year 01

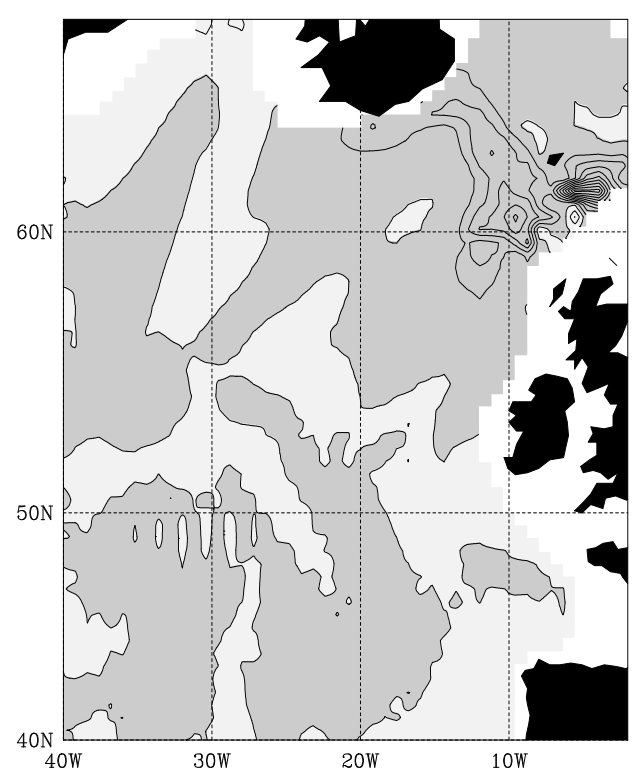

$\operatorname{delta}(\mathrm{T}),[\mathrm{S} 6]-[\mathrm{S} 9]$, year or

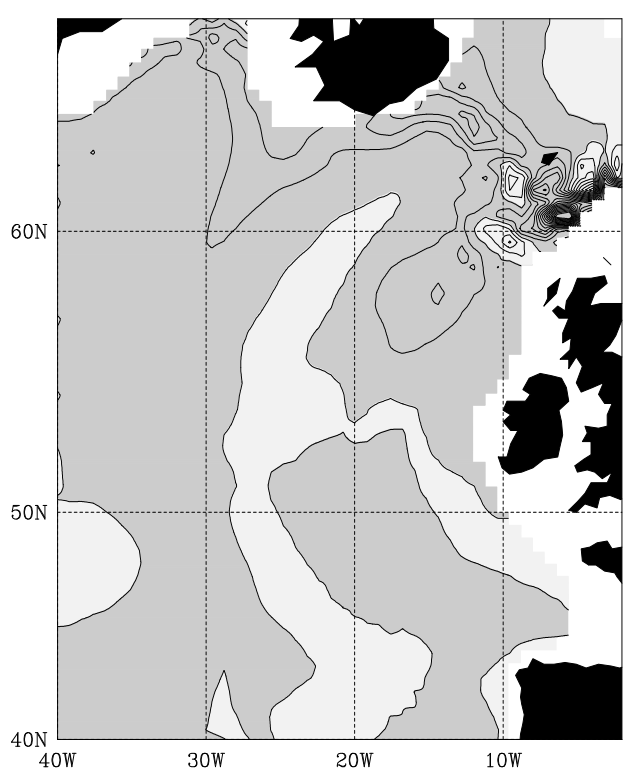

$\operatorname{delta}(\mathrm{T}),[$ S6 $]-[S 9]$, year 03

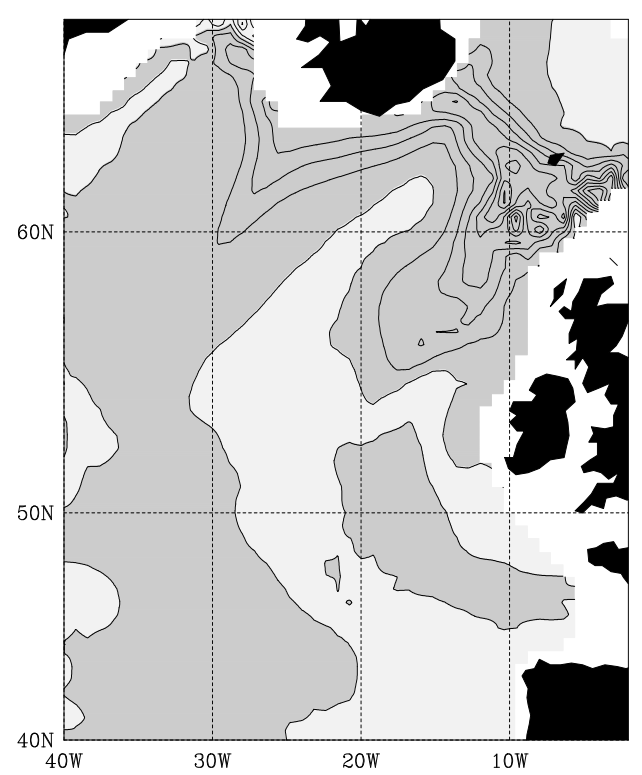

$\operatorname{delta}(\mathrm{T}),[\mathrm{S} 6]-[\mathrm{S} 9]$, year 19

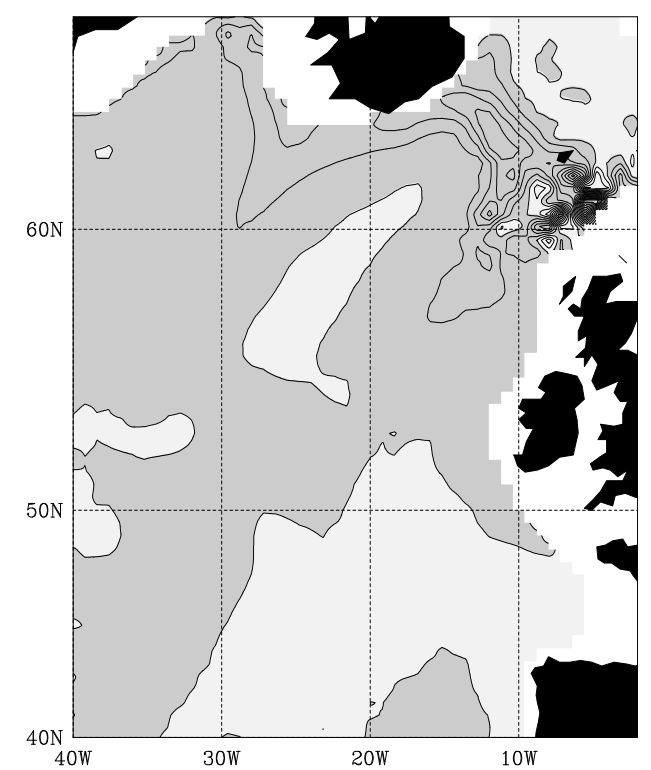

Figure 10 
$\operatorname{delta}(\mathrm{PSI}),[\mathrm{S} 6]-[\mathrm{S} 9]$, year 01

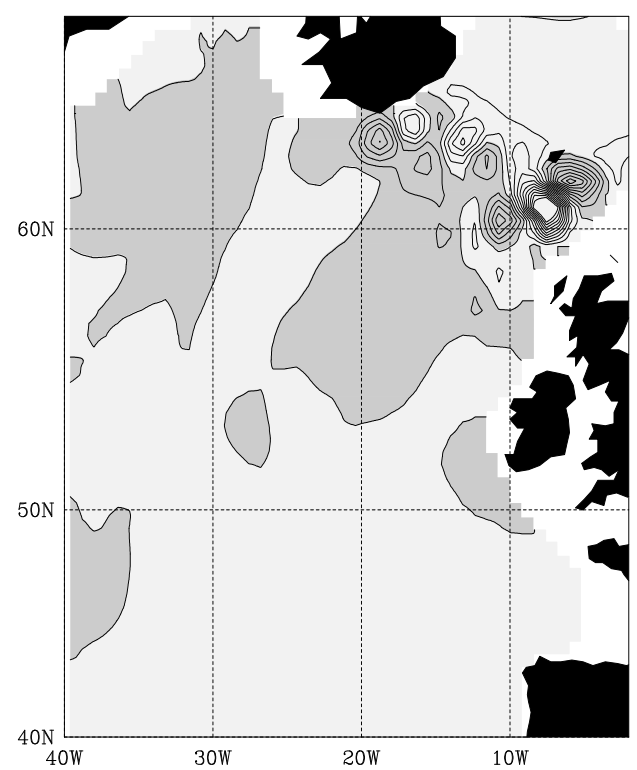

$\operatorname{delta}(\mathrm{PSI}),[\mathrm{S} 6]-[\mathrm{S} 9]$, year Or

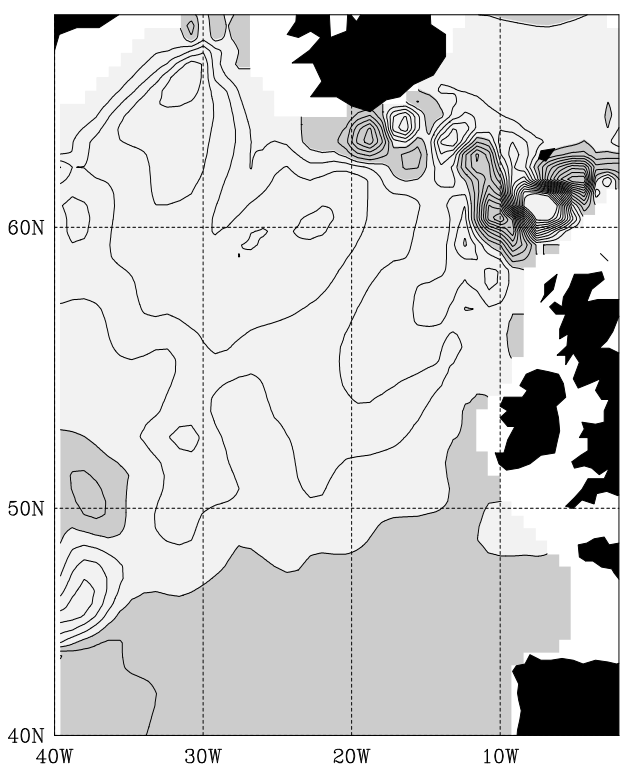

delta(PSI), [S6] - [S9], year 03

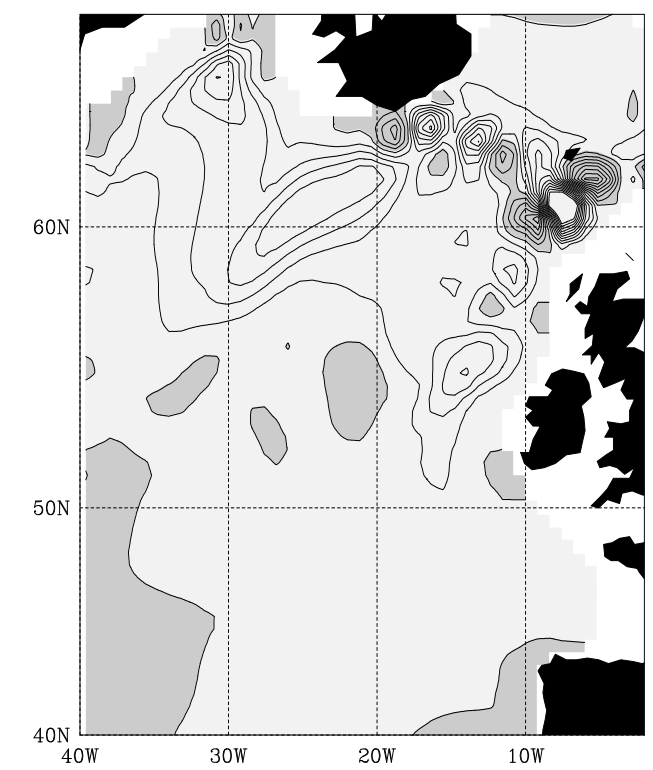

delta(PSI), [S6] - [S9], year 19

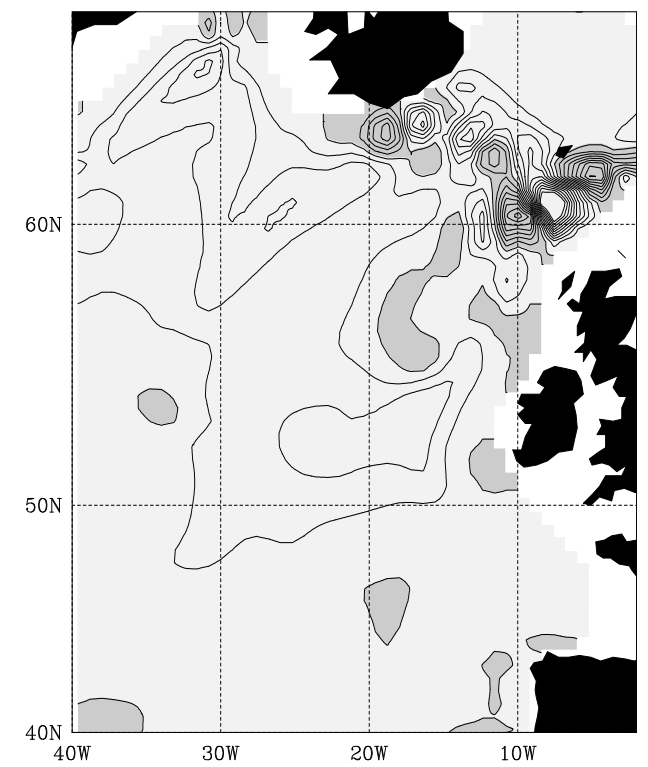

Figure 11 
delta(Jebar), [S6] - [S9], year 01 delta(Jebar), [S6] - [S9], year 03
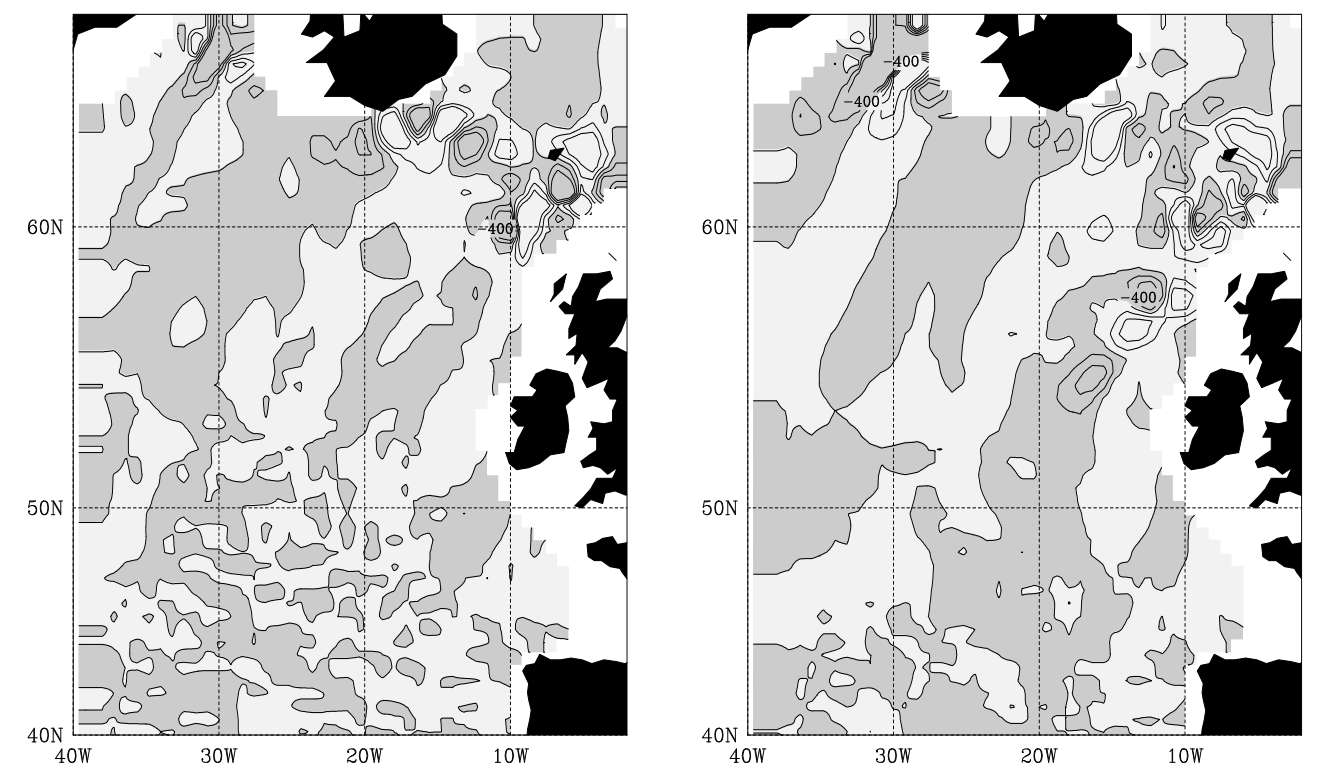

$\operatorname{delta(Jebar),~[S6]-[S9],~year~Or~}$

delta(Jebar), [S6] - [S9], year 19
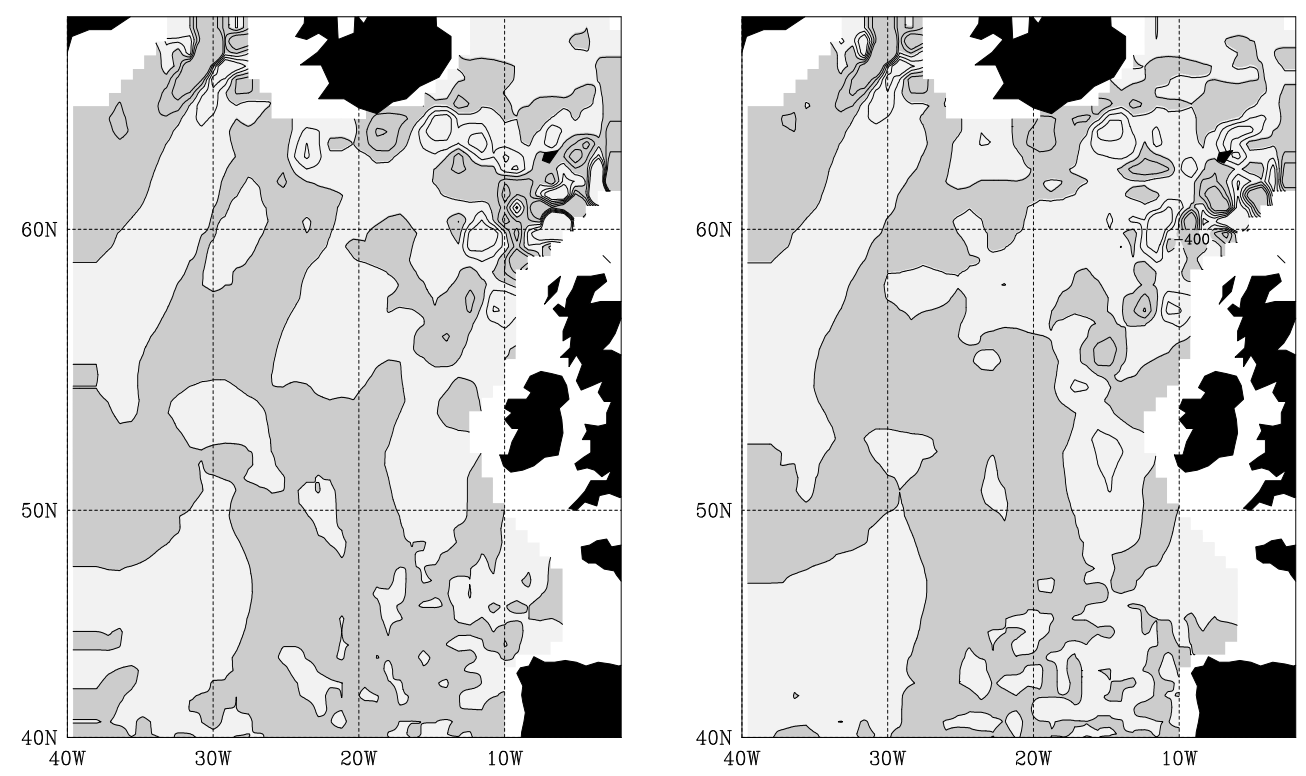

Figure 12 